\title{
International Trade, Income Distribution and Welfare*
}

\author{
Phillip McCalman \\ Department of Economics \\ University of Melbourne
}

October 2017

\begin{abstract}
This paper studies the relationship between income distribution and international integration in a canonical trade setting with one change. In the standard model prices are solely a function of (constant) marginal costs and (constant) elasticities, implying that information on individual incomes are of no value to a firm. To allow a more realistic role for consumer level information, a firm's strategy space is expanded to include non-linear prices. Now profit maximizing firms use information on income distribution to design a product for each income class and set prices to induce each group to optimally select the appropriate option. Equilibrium involves designs below the first best for low income groups and above the first best for high income groups - welfare differences are more exaggerated than income differences. When countries with differing income distributions integrate this has implications for the size of these distortions, influencing the gains from trade both within and across countries. These implications are quantified and shown to be potentially significant factors affecting welfare outcomes from integration - with the consequences more pronounced at lower trade costs. The structure of trade and expenditure patterns that emerge also match a range of empirical findings. These results are driven by firm strategy based on income difference alone as preferences are assumed to be identical and homothetic across countries, placing the distribution of income at the center of the analysis.
\end{abstract}

Key Words: Intra-industry trade, monopolistic competition, inequality JEL Classifications: F12, F15, F60

\footnotetext{
${ }^{*}$ I would like to thank Andres Rodriguez-Clare, along with two anonymous referees for valuable comments and suggestions. The paper also benefited from numerous seminars and presentations. Financial support from Peter B. Kenen Fellowship at Princeton University and the Australian Research Council, Grant DP-140101128, are gratefully acknowledged.
} 


\section{Introduction}

Models of international trade have traditionally used richness on the supply side to gain insight into why countries trade and the likely implications of integration. Any role for consumer heterogeneity is usually suppressed by adopting preferences that are both identical and homothetic. While analytically convenient, these assumptions (coupled with linear pricing) lead models of international trade to effectively ignore some of the most pronounced differences across individuals, regions and countries: income and spending patterns.

To date all efforts to gain insight into the consequences of this variation have started by relaxing the assumption of homotheticity, freeing up expenditure shares to depend not just on relative prices but also income levels. In contrast, this paper maintains the assumption of homothetic preferences and focuses on an alternative possibility - firms themselves might be interested in income differences, and may try to exploit this information to raise profits. That is, firms may try to discriminate across the different income groups.

To isolate the main implications of this behavior, we adopt the preference and technology structure of Krugman (1980). With homothetic preferences at its heart, this shuts down the mechanisms exploited by the previous literature. ${ }^{1}$ Furthermore, its single sector structure means that expenditure shares don't vary with income. Nevertheless, differences in income across consumers translate into different consumer level demand functions. What we explore is the possibility that a firm might find a way to use this information to their advantage. Another benefit of this framework is that we have a very well understood benchmark for thinking about welfare - as set out in Arkolakis et al. (2012). Can we offer anything new in a setting where welfare outcomes are remarkably robust to variation in assumptions on market structure and firm heterogeneity? Despite all this structure intended to suppress any role for consumer heterogeneity and deliver broad welfare results, we show that nevertheless the gains from trade can vary across income groups within a country.

The key feature that drives this result is that we allow firms to not only recognize that

\footnotetext{
${ }^{1}$ In our application we find it more intuitive to assume that consumers have preferences over the quality of the varieties that are aggregated in a CES utility function - section 2 provides details. Consequently, doubling of a consumer's income will double their demand for quality of a variety at any given per unit price - the location of demand is proportional to income.
} 
consumers have different incomes but also be sophisticated enough to exploit this knowledge. The way firm set prices in Krugman (1980) lacks this level of sophistication. In particular firms are assumed to use linear prices, implying they are only interested in the curvature of the residual demand function when formulating their optimal strategies. Moreover, with CES preferences the elasticity of residual demand is constant and the same for all consumers. The combination of these two assumptions has relatively extreme implications for how firms respond as their information set is enriched. For example, if a firm is suddenly able to observe the income levels of each consumer, the best they can do under linear pricing is implement third degree price discrimination. However, with the elasticity of demand independent of income and the same for all consumers, a firm will not change their behavior, continuing to charge the same price per unit to all types. Contrary to what might be imagined, this additional consumer level information is then essentially of no value to a firm.

To incorporate a more realistic role for how this information is utilized, we expand a firm's strategy space to include non-linear prices. We follow the typical approach and assume that a firm knows the distribution of income but not an individual consumer's income. More formally this is a setting where a firm implements second degree price discrimination (SDPD). If a firm optimally chooses to exploit this consumer heterogeneity, it does so through the design of a menu of options (product line or "versioning") offered to a consumer. $^{2}$

A particularly neat illustration of a product line is the iPad range. The initial offerings only had one dimension of variation, the quantity of gigabytes (GB): 16GB, 32GB and 64GB. For the first two sizes the prices are $\$ 499$ and $\$ 599 .{ }^{3}$ If we use these prices to linearly project the price of a 64GB machine we arrive at $\$ 399+\$ 6.25(64)=\$ 799$, which is $\$ 100$ more than the actual price of $\$ 699 .{ }^{4}$ What's behind this pricing behavior - differences in cost, elasticity or something else? Industry sources confirm that the marginal cost of a GB is constant, so costs can't explain this variation. Additionally, the prices imply that the elasticity of de-

\footnotetext{
2See Shapiro and Varian (1998) and Phillips (2005) for a general discussion of "versioning" in the management literature.

${ }^{3}$ Apple typically refreshes its product line on an annual basis and occasionally has added additional sizes. However, the lower end of the product line is updated less frequently and remains in production longer.

${ }^{4}$ To put this number in context, the additional assembly cost of onshoring the closely related iPhone has been estimated at around \$65, "How the US lost out on iPhone work," The New York Times, 21 January, 2012.
} 
mand is increasing in memory size, contrary to the typical assumption. ${ }^{5}$ Using the implied elasticity from the 16GB machine suggests that the 64GB iPad would be priced over $\$ 1100$. Evidently a simple mark-up formula isn't employed, leaving scope for more sophisticated pricing strategies underlying product menus and their design. Moreover, the widespread use of product lines raises a broader question about their welfare implications, not only for a single product but also at an aggregate level. ${ }^{6}$ A natural way to capture the broader welfare consequences of SDPD is through a general equilibrium framework - the approach adopted in this paper.

An important characteristic of SDPD is that firm behavior and the resulting monopolistically competitive equilibrium is not just a function of the curvature of the demand functions but also their position. Specifically, the profit maximizing menu trades off the desire to extract rents from an income group (by offering a design close to the first best) against the cost that this provides an enhanced outside option for another income group/s. This trade-off is resolved by the relative size and frequency of income groups. As a consequence the distribution of income is a fundamental determinant of the design of the equilibrium product line.

A feature of this equilibrium is that product design is distorted relative to the first best. In general, products designed for low income types are below the first best, while the products targeted to the high income groups are above the first best. ${ }^{7}$ It then follows that welfare differences are more exaggerated than income differences.

The critical role of the distribution of income in this outcome immediately implies that the integration of two countries with different income distributions alters product line design and consequently welfare. Insight into the implications are clearest when countries can be ranked in terms of income distribution. In particular, if a country's income distri-

\footnotetext{
${ }^{5}$ The ordering of price elasticities follows from $\sigma=p /(p-c)$.

${ }^{6}$ Empirical studies that document these practices include retail gasoline (Shepard (1991)), textbooks (Clerides (2002)), automobiles (Verboven (2002)), telecommunications (Miravete and Röller (2003)), advertising (Busse et al. (2005)), cable TV (Crawford and Shum (2007)), fast food (McManus (2007)), paper products (Cohen (2011), Palazzolo and Orhun (2016)), personal computers (Eizenberg (2014)), CPUs (Nosko (2010)), soft drinks (Marshall (2015), Hendel and Nevo (2013)). In addition to these products many other sectors use product lines but untangling cost and markup changes is often not straightforward. Another example where marginal cost is likely to be constant is the perfume industry. Consider Chanel $N^{o} 5$ - the best selling perfume in the world - is sold in three sizes, with the price per oz of the largest bottle $35 \%$ lower than the smallest bottle. This translates to a saving of $\$ 175$ for buying the larger bottle.

${ }^{7}$ Monopoly models of SDPD predict the first result but not the second. See for example Maskin and Riley (1984).
} 
bution dominates the global distribution then the gains from free trade will be larger than predicted by the sufficient statistic measure developed by Arkolakis et al. (2012) (henceforth ACR). ${ }^{8}$ Moreover, these gains are disproportionately concentrated at the bottom end of the income distribution. In this case, trade reduces the distortions from SDPD and the benefits are felt across the entire distribution of income. The opposite occurs in a country whose income distribution is dominated by the global distribution, as trade adds to the distortions from SDPD. Since these distortions are not captured by the standard model of international trade they represent a new dimension of welfare analysis.

Further insight follows from decomposing the gains from trade into those derived from additional varieties and those associated with the design of the menu of choices. Critically, these two components respond differentially to the level of trade costs. In particular, when trade barriers are relatively high, incremental liberalization is primarily about reducing the costs of serving a market and has little impact on menu design. Thus, for high trade barriers the gains from marginal liberalization follow a pattern familiar from the standard model and consistent with ACR. However, once trade barriers become sufficiently low, the potential for international arbitrage triggers a process of convergence in product design across countries. Since not all types in all countries gain from design convergence, there is potential for an incremental process of trade liberalization to stall - at the margin the negative effects for product design in one country can outweigh further savings from lower trade costs.

To examine the role of this mechanism, the model is quantified on the same data utilized by Costinot and Rodriguez-Clare (2014) (hereafter CRC). In common with CRC, the SDPD model has a component of welfare determined by the domestic expenditure share and the trade elasticity. In addition, this measure is multiplied by an adjustment factor that depends on product design. While decreases in domestic expenditure share raise welfare, changes in product design can be an offsetting force. To determine design changes, the equilibrium designs are derived for each income group in each country based on the observed national income distribution. The counter factual considered is complete integration - designs based on the global income distribution. The ratio of the design changes for each income group

\footnotetext{
${ }^{8}$ Given the primitives of the model are from Krugman (1980), ACR predict that a sufficient statistic for welfare gains can be constructed based on the domestic expenditure share and the trade elasticity.
} 
generates an adjustment factor that either magnifies the ARC gains or diminishes them. Since the domestic expenditure share associated with free trade is not readily calculated, the metric adopted is to ask what change in the domestic expenditure share is required to ensure every income group gains from integration. That is, what percentage change in domestic expenditure share is required to offset any negative design changes?

This exercise reveals stark differences across countries. In particular, only 5 countries have all income groups benefit unambiguously from design changes induced by integration. In contrast, the remaining 28 countries all have at least one income group that is adversely affected by the negative consequences of menu redesign. These changes are especially daunting in low income countries. For 12 countries, the change in the domestic expenditure share needed to offset these design changes exceeds 10 percentage points requiring a larger decline in the domestic share than observed for any of these countries between 1995 to 2008. Consequently, in these countries it seems likely that there is at least one income group that would prefer the initial trade equilibrium to full integration. These results suggest that if the negative consequences of standardizing global product lines are disproportionately associated with future liberalization, then a number of countries may resist efforts to fully integrate markets through reductions in trade barriers and/or harmonization of standards/regulations.

This paper is related to the literature on international trade that incorporate non-homothetic preferences. Simonovska (2015) shares a focus on price discrimination. She is interested in understanding how prices vary with per capita income across countries in a setting of third degree price discrimination, with no discrimination within countries. However, she doesn't consider the welfare implications of international integration and quality also doesn't vary by destination. Tarasov (2012), Fajgelbaum et al. (2011) and Choi et al. (2009) develop models that examine quality choice by firms when higher income consumers purchase higher quality products. However, these models don't allow firms to exploit the underlying heterogeneity in the population through the design of a menu of choices. Instead they constrain a firm to produce a good with a single quality level and then leverage this feature through the location choices of firms that produce different qualities. The multi-sector analysis demonstrates that a model with homothetic preferences and SDPD is capable of generating a non- 
linear Engel curve - the very feature that motivates the use of non-homothetic preferences. ${ }^{9}$ The key difference is whether distortions arise. In models that utilize non-homotheticities, equilibrium doesn't necessarily involve inefficiencies (Fajgelbaum and Khandelwal (2015), Markusen (2013), Fieler (2011) and Choi et al. (2009)) while the equilibrium associated with SDPD is inefficient. Hence, understanding the source of the variation in expenditure patterns has welfare implications. While I have emphasized differences with the literature based on non-homethetic preferences, there is also scope for these two approaches to be integrated. The adoption of homothetic preferences in the current paper serves to highlight the independent role of discriminatory practices by firms in shaping outcomes and welfare but these practices are also consistent with richer demand structures.

The remainder of the paper is broken into three sections. Section 2 constructs a general equilibrium monopolistically competitive model of SDPD with two income types. This framework facilitates comparisons with both the previous trade literature based on general equilibrium models with linear pricing and also the partial equilibrium monopoly literature that analyzes SDPD. In particular, it derives the shadow linear prices underlying SDPD and the associated measure of real income that enable non-linear prices to be analyzed in a general equilibrium setting. Section 3 considers integration between countries with different income distributions, and examines the consequences of different levels of trade costs. The final section quantifies the welfare effects of integration in a world where firms implicitly discriminate through product lines.

\section{Model}

The main elements of the model are familiar from Krugman (1980): one factor (inelastically supplied), monopolistic competition between a set of symmetric firms with a constant marginal cost (and unit labor requirement), $w$, and a firm level fixed cost, $w F$. There is a

\footnotetext{
${ }^{9} \mathrm{~A}$ multi-sector version of the model is developed in the appendix which confirms the potential for nonlinear Engel curves in a model with identical and homothetic preferences.
} 
single sector where consumers have the same CES preferences over products: ${ }^{10}$

$$
U=\left[\sum_{v} q_{v}^{\rho}\right]^{1 / \rho} \quad \text { and } 0<\rho<1
$$

To connect with the motivating examples $q_{v}$ is interpreted as denoting quality (e.g. GB's). This implies we are also assuming that a consumer will purchase one unit of each variety. Nevertheless, since $q_{v}$ is continuous, the quality interpretation preserves the homotheticity of preferences.

To add within country income variation, these basic features are augmented by including two types of workers who differ in terms of labor endowment. A low type has an endowment of $L^{L}$ while the high type possesses $L^{H}$. Letting $\beta_{i}$ denote the fraction of population of country $i$ that is high type, then country $i$ has an aggregate endowment of $L_{i}=\beta_{i} L^{H}+\left(1-\beta_{i}\right) L^{L}{ }^{11}$ Normalizing the population in a given country to unity implies that there is variation within countries due to individual endowment differences as well as variation across countries due to aggregate differences in endowments. ${ }^{12}$ Note that simply adding within country income variation to Krugman (1980) does not alter any of that model's results, the key departure involves allowing firms to utilize information on income distribution when setting non-linear prices.

These non-linear prices are implemented as a menu of options offered to consumers, $\{T(q), q\}$, where $T(q)$ is the payment required for a product with attribute $q$. While a firm would like to extract all the surplus from a consumer, it is constrained by the fact it only knows the distribution of income and not the income of any individual. From the literature on SDPD, we know in this setting a firm designs the menu $\{T(q), q\}$ subject to a set of incentive compatibility (each income group prefers the option designed for them) and participation constraints (a consumer's net pay-off has to be non-negative).

\footnotetext{
${ }^{10}$ Note that the standard interpretation in the trade literature of $q_{v}$ is as a quantity. This fits most closely products like perfume. However, based on the iPad example it is also possible to interpret $q_{v}$ as quality, measured by Gigabytes. The specification of preferences is flexible enough to accommodate either interpretation but not simultaneously within the same sector. The appendix presents a multi-sector version of the model that allows for cross sector differences in the nature of the product.

${ }^{11} \mathrm{We}^{\prime} \mathrm{ll}$ use superscripts to track individual characterstics (income, prices, designs) and subscripts to index country characteristics.

${ }^{12} \mathrm{~A}$ discrete distribution is not critical for any of the results. The main advantage is a more direct mapping to national and global income distributions which are based on income bins (see Lakner and Milanovic (2015)) and used in section 4 . That section also allows the number of income groups to be greater than two but the intuition is neatly captured by the two point distribution.
} 
These constraints accommodate a wide range of possibilities, including the option to use linear prices, as in Krugman (1980). In this case, a firm would offer two options: $\left\{T^{I}\left(q^{I}\right)=\frac{w}{\rho} q^{I}, q^{I}\right\}$, where $q^{I}$ corresponds to the quality demanded by an individual with income $I$ when confronted with a price per unit of quality of $\frac{w}{\rho} \cdot{ }^{13}$ Which menu a firm offers depends on how they anticipate a consumer will behave. Thus, to solve the model, we start by considering the consumer choice problem when presented with a discrete set of options by a firm.

\subsection{Budget Constraint}

The first step in analyzing consumer choice is to consider the budget constraint. Observe that a utility maximizing consumer will exhaust their budget: $m^{I}=\sum_{v} T_{v}^{I}\left(q_{v}^{I}\right)$. At first this representation appears difficult to square with the typical approach to consumer optimization based on linear prices. However, we can convert the menus offered by firms into something more familiar by recovering the shadow linear prices associated with the options embodied in a menu.

To do so we first note that a consumer faces an incentive compatible menu from a firm. That is, each income group purchases the item intended for them. In particular, a consumer with income $I$, selects $q_{v}^{I}$. Since $q_{v}^{I}$ is set by the firm, a consumer does not have discretion over this value. Consequently, the shadow price is then the linear price, $p_{v}^{I}$, which would result in the choice of $q_{v}^{I}$ by a consumer with income $I$. Given the CES demand system, this shadow price is $p_{v}^{I}=\theta^{I}\left(q_{v}^{I}\right)^{\rho-1}$, where $\theta^{I}$ determines the position of the residual demand curve. Hence, expenditure based on per unit consumption is $p_{v}^{I} q_{v}^{I}$.

Since we have argued above that $T_{v}^{I}>p_{v}^{I} q_{v}^{I}$ should be included as a possibility, there is also a component of the total payment that isn't analogous to standard per unit expenditure. Call this component, $A_{v}^{I}$, where $A_{v}^{I}=T_{v}^{I}-p_{v}^{I} q_{v}^{I}$. Consequently, $T_{v}^{I}$ is associated with an implicit set of prices $p_{v}^{I}, A_{v}^{I}$. This then implies:

$$
m^{I}=\sum_{v} T_{v}^{I}=\sum_{v}\left(A_{v}^{I}+p_{v}^{I} q_{v}^{I}\right)
$$

From a modeling perspective this representation has the advantage that $A_{v}^{I}$ acts like a lump

\footnotetext{
${ }^{13}$ This pricing satisfies the participation and incentive constraints and is therefore feasible.
} 
sum tax, allowing the budget constraint to be expressed in the usual form. Therefore, rearranging this equation, a consumer with gross income $m^{I}$ has net income:

$$
\bar{m}^{I}=m^{I}-\sum_{v} A_{v}^{I}=\sum_{v} p_{v}^{I} q_{v}^{I}
$$

Hence, the main modification to the model is in relation to net income. In the standard model (i.e. linear prices) there is no difference between net and gross income $\left(\bar{m}^{I}=m^{I}\right)$. However, under non-linear prices net income can diverge from gross income. It is worth reiterating that firms offer $\left\{T_{v}^{I}, q_{v}^{I}\right\}$ and not $\left\{A_{v}^{I}, p_{v}^{I}\right\}$. Nevertheless, utilizing the shadow linear prices facilitates a more conventional analysis in a general equilibrium setting. In particular, utility maximization can be evaluated using the standard technique of constrained optimization.

\subsection{Consumer Optimization}

Apart from using net income rather than gross income, the utility maximization program results in familiar expressions with the inverse demand for a variety targeted at consumer $I$ by firm $v: \quad p_{v}^{I}=\theta^{I}\left(q_{v}^{I}\right)^{\rho-1}$. Note that $\theta^{I}=\frac{\bar{m}^{I}}{\left(Q^{I}\right)^{\rho}}$ determines the location of residual demand and, as usual, is determined by the level of income $\left(\bar{m}^{I}\right)$ and competitors aggregate behavior $\left(Q^{I}=\left[\sum_{v}\left(q_{v}^{I}\right)^{\rho}\right]^{1 / \rho}\right)$. In the standard model income is not influenced by equilibrium outcomes. However, under SDPD, $\bar{m}^{I}$ will include information rents and therefore is determined in equilibrium (it is derived below).

Facing these residual demand curves a typical firm evaluates the surplus from serving consumer $I$ in the following way:

$$
S_{v}^{I}(q)=\theta^{I} \int_{0}^{q_{v}^{I}} z^{\rho-1} d z=\frac{\theta^{I}\left(q_{v}^{I}\right)^{\rho}}{\rho} .
$$

Note that since firms are assumed to be monopolistically competitive, they take the marginal utility of income as constant. This allows them to consider the area under the residual demand curve in monetary terms. 


\subsection{Profit Maximizing Product Lines}

Using these surplus functions and the information on the distribution of types in the population, a typical monopolistically competitive firm chooses a menu of $\left\{T^{I}, q^{I}\right\}, I \in\{L, H\}$ to maximize

$$
\pi=\beta\left(T^{H}-w q^{H}\right)+(1-\beta)\left(T^{L}-w q^{L}\right)-w F
$$

subject to

$$
\begin{aligned}
& \theta^{H} \frac{\left(q^{H}\right)^{\rho}}{\rho}-T^{H} \geq \theta^{H} \frac{\left(q^{L}\right)^{\rho}}{\rho}-T^{L} \quad \& \quad \theta^{L} \frac{\left(q^{L}\right)^{\rho}}{\rho}-T^{L} \geq \theta^{L} \frac{\left(q^{H}\right)^{\rho}}{\rho}-T^{H}, \\
& \theta^{L} \frac{\left(q^{L}\right)^{\rho}}{\rho}-T^{L} \geq 0 \quad \& \quad \theta^{H} \frac{\left(q^{H}\right)^{\rho}}{\rho}-T^{H} \geq 0 .
\end{aligned}
$$

where (2) are the incentive compatibility constraints while (3) are the participation constraints. In a monopoly non-linear pricing problem the ordering of the $\theta^{\prime} s$ is enough to ensure that the single crossing property holds - implying that only two of these constraints bind, the incentive constraint for the high and the participation constraint for the low type. ${ }^{14}$ However, since the $\theta^{\prime}$ s are determined as part of an equilibrium outcome we cannot simply take for granted that $\theta^{H}>\theta^{L}$. Nevertheless, we conjecture that this ordering holds (it is in fact satisfied in equilibrium) allowing the relevant constraints to be rewritten as:

$$
\begin{aligned}
T^{L} & =\theta^{L} \frac{\left(q^{L}\right)^{\rho}}{\rho}, \\
T^{H} & =\left(\theta^{H} \frac{\left(q^{H}\right)^{\rho}}{\rho}-\theta^{H} \frac{\left(q^{L}\right)^{\rho}}{\rho}\right)+T^{L}=\theta^{H} \frac{\left(q^{H}\right)^{\rho}}{\rho}-\left(\theta^{H}-\theta^{L}\right) \frac{\left(q^{L}\right)^{\rho}}{\rho} .
\end{aligned}
$$

These prices imply that while a firm can extract all the surplus under the residual demand curve of the low income consumer, the high income consumer is able to capture information rents, $\left(\theta^{H}-\theta^{L}\right) \frac{\left(q^{L}\right)^{\rho}}{\rho}$, by having the low types product as their outside option. These prices imply total revenues, along with total costs, of:

$$
\begin{aligned}
& T R=(1-\beta) T^{L}+\beta T^{H}=\left(\theta^{L}-\beta \theta^{H}\right) \frac{\left(q^{L}\right)^{\rho}}{\rho}+\beta \theta^{H} \frac{\left(q^{H}\right)^{\rho}}{\rho}, \\
& T C=(1-\beta) w q^{L}+\beta w q^{H}+w F .
\end{aligned}
$$

\footnotetext{
${ }^{14}$ See Maskin and Riley (1984).
} 
Taking first order conditions with respect to $q^{I}$ defines a firm's optimal behavior:

$$
\begin{aligned}
\theta^{H}\left(q^{H}\right)^{\rho-1} & =w, \\
\left(\theta^{L}-\beta \theta^{H}\right)\left(q^{L}\right)^{\rho-1} & =(1-\beta) w .
\end{aligned}
$$

The value function is derived by observing that (6) is homogeneous of degree $\rho$ in the vector of production designs, $q^{I}$, which implies $\sum_{I} \frac{\partial T R}{\partial q^{I}} q^{I}=\rho T R$. Since marginal revenue of any design equals (constant) marginal cost it follows from (8) \& (9) that the value function can be written as $\frac{1-\rho}{\rho} \sum_{I} \beta^{I} w q^{I}-w F$. Setting this equal to zero confirms that free entry output/characteristics must satisfy:

$$
\sum_{I} \beta^{I} q^{I}=F(\sigma-1)
$$

where $\sigma=\frac{1}{1-\rho}$ is the elasticity of demand. ${ }^{15}$ This implies that the average attributes of a firm's product line is the same as chosen by a social planner and also coincides with what arises in the standard model with linear prices. Given the aggregate endowment of labor is fixed, this implies the equilibrium number of firms, $n_{i}$, is also first best in this single sector setting. ${ }^{16}$

\subsection{Equilibrium}

Having derived the equilibrium production of each firm, the second issue is the allocation across income groups. As a benchmark, note that the linear price model generates an efficient outcome since the equilibrium allocation across the two groups is proportional to income. That is, the ratio of designs coincides with $\frac{L^{L}}{L^{H}} \equiv \eta$. To determine the allocation

\footnotetext{
${ }^{15}$ This condition implies that average revenue equals $w / \rho$. This gives the impression that a firm implementing a fixed per unit price of $w / \rho$ could also achieve the same outcome. However, this is not the case. To see this note that the average revenue function for a firm implementing SDPD for income group $I$ is $A R^{I}=T^{I} / q^{I}=A^{I} / q^{I}+p^{I}$. Hence, the average revenue function lies outside of the inverse demand function, $p^{I}$. So a linear pricing firm would earn an average revenue of $w / \rho$, but it would sell fewer units than $q$ and consequently have a higher average cost - implying negative profits in equilibrium for this strategy.

${ }^{16} \mathrm{To}$ see that this result is not dependent on a discrete distribution, let $f(\theta)$ be the density of a continuous distribution. Standard techniques allow a firm's profit function to be written as: $\quad \pi=\int_{\theta_{L}}^{\infty}\left(\frac{\theta q(\theta)^{\rho}}{\rho}-\frac{1-F(\theta)}{f(\theta)} \frac{q(\theta)^{\rho}}{\rho}-w q(\theta)\right) f(\theta) d \theta-w F$. The associated first order conditions imply $\left(\theta-\frac{1-F(\theta)}{f(\theta)}\right) q^{\rho-1}=w$, so the profit function becomes $\int_{\theta_{L}}^{\infty}\left(\frac{w q(\theta)}{\rho}-w q(\theta)\right) f(\theta) d \theta-w F$. Setting $\pi=0$ implies that $\int q(\theta) f(\theta) d \theta=F(\sigma-1)$.
} 
when firms implicitly discriminate, start by combining (8) and (9):

$$
\left(\frac{\theta^{L}}{\theta^{H}}-\beta\right)\left(\frac{q^{L}}{q^{H}}\right)^{\rho-1}=1-\beta
$$

Recall that $\theta^{I}=\frac{\bar{m}^{I}}{\left(Q^{I}\right)^{\rho}}=\frac{\bar{m}^{I}}{n\left(q^{I}\right)^{\rho}}$. Consequently, $\frac{\theta^{L}}{\theta^{H}}=\frac{\bar{m}^{L}}{\bar{m}^{H}}\left(\frac{q^{H}}{q^{L}}\right)^{\rho}$. To make the notation more compact, denote relative design by $\phi \equiv \frac{q^{L}}{q^{H}}$ and relative net income by $v \equiv \frac{\bar{m}^{L}}{\bar{m}^{H}}$ which implies $\frac{\theta^{L}}{\theta^{H}}=\frac{v}{\phi^{\rho}}$.

We will focus specifically on the relative design of products, $\phi$. Using these expressions, the equilibrium conditions for relative design can be derived as:

$$
\beta \phi^{\rho}+(1-\beta) \phi=\nu
$$

To complete the equilibrium characterization, we need to solve for the net incomes, $\bar{m}^{I}$. For the low type, net income follows from (4):

$$
\rho T^{L}=\theta^{L}\left(q^{L}\right)^{\rho}=\frac{\bar{m}^{L}}{n} \quad \Rightarrow \rho n T^{L}=\rho m^{L}=\bar{m}^{L} .
$$

For the high income group (5) implies: ${ }^{17}$

$$
\rho T^{H}=\theta^{H}\left(q^{H}\right)^{\rho}\left(1-\phi^{\rho}\right)+\rho T^{L} \Rightarrow \bar{m}^{H}=\frac{\rho\left(m^{H}-m^{L}\right)}{1-\phi^{\rho}} .
$$

Combining these with (11) and recalling $\eta=\frac{L^{L}}{L^{H}}$, equilibrium product designs must satisfy:

$$
(\eta+\beta(1-\eta)) \phi^{\rho}+(1-\beta)(1-\eta) \phi=\eta
$$

Inspecting this system it is immediately apparent that any solution is determined solely by the distribution of income, $\beta$, since $\eta$ and $\rho$ are parameters. ${ }^{18}$ Moreover as $\eta>0$ and the LHS is monotonically increasing in $\phi$, the solution to this equation exists and is unique. Furthermore, the coefficients on $\phi^{\rho}$ and $\phi$ sum to one, consequently $\phi^{\rho}>\eta>v>\phi>0 .{ }^{19}$

\footnotetext{
${ }^{17}$ For the continuous case, $T(\theta)=\theta \frac{q(\theta)^{\rho}}{\rho}-\int_{\theta_{L}}^{\theta} q^{\rho}(v) d v$ which implies $\bar{m}(\theta)=\rho m(\theta)+\int_{\theta_{L}}^{\theta} q^{\rho}(v) d v$.

${ }^{18}$ See section the appendix for a multisector model that allows $\rho$ to vary across sectors.

${ }^{19} \eta>v$ follows from subtracting (11) from (14).
} 
Using this ordering and totally differentiating (14) with respect to $\beta$, generates:

$$
\frac{d \phi}{d \beta}=\frac{(1-\eta)\left(\phi^{\rho}-\phi\right)}{\rho \phi^{\rho-1}(\eta+\beta(1-\eta))+(1-\beta)(1-\eta)}<0
$$

Consequently, the equilibrium quality of the low end product relative to the high end product is declining in $\beta$.

A distinctive aspect of this equilibrium is the distribution of quality across the income groups. As identified above, the aggregate feature of each firm is first best, but this property doesn't carry over to the products offered to each income group. ${ }^{20}$

PROPOSITION 1. For any non-degenerate income distribution, each firm always designs a menu that induces the low income group to purchase a product below the utilitarian first best while offering the high income group a product that is above the utilitarian first best.

This proposition is the basis of the difference between the current model and the previous trade literature and also helps to distinguish between partial and general equilibrium models of SDPD. With this in mind there are three features to highlight. ${ }^{21}$

First, in contrast to a model with linear pricing - which generates a first best allocation in a single sector setting - distortions exist in equilibrium. These distortions result from a firm's differential ability to extract rents from the various income groups.

Second, market power distorts output decisions both above and below the first best. While the usual downward monopoly distortion is evident for the low income group, it is always the case that the high income group receives a product above the first best. Outcomes above the social optimum provide a stark contrast to the linear price trade model. Note also that this result doesn't arise in the canonical monopoly model of SDPD where the high type always receives the first best outcome (see Maskin and Riley (1984)). In that

\footnotetext{
${ }^{20}$ To see how the allocation varies from the first best for continuous distributions, consider the first order conditions for the allocation under SDPD and for the first best (denoted by $\left.{ }^{*}\right):\left(\theta-\frac{1-F(\theta)}{f(\theta)}\right) q^{\rho-1}=w$ and $\theta^{*}\left(q^{*}\right)^{\rho-1}=w$. Combining these two implies $\frac{q}{q^{*}}=\frac{\bar{m}}{\rho m}\left(1-\frac{1-F(\theta)}{\theta f(\theta)}\right)$. To show that the high type is over served (relative to the first best) in equilibrium, use the definition of $\bar{m}$ to obtain $\frac{q^{H}}{q^{H *}}=\frac{\rho m^{H}+\int_{\theta^{H}}^{\theta^{H}} q^{\rho}(v) d v}{\rho m^{H}}>1$. Combining this over service with the fact that the scale of production is first best implies that it must be the case $\frac{q^{L}}{q^{L *}}=\frac{\rho m^{L}}{\rho m^{L}}\left(1-\frac{1}{\theta^{L} f\left(\theta^{L}\right)}\right)<1$.

${ }^{21}$ Proposition 1 also arises in other demand systems, and in that sense is not solely a function of the CES structure. For an analysis based on the Melitz and Ottaviano (2008) demand system see McCalman (2016a). For a model with both consumer and firm heterogeneity see McCalman (2017).
} 
setting the positions of the residual demand curves are exogenous (i.e. $\theta^{I}$ is given) and there is a single firm. Relaxation of either of these features can play a role in the result that a high income type is offered a product above the first best.

In this single sector setting, the position of a residual demand curve is influenced by the net income of a consumer type. For the high income types, the capture of information rents raises their net income and consequently shifts their residual demand function out relative to the first best. ${ }^{22}$ Conditional on the position of this residual demand curve a firm has no incentive to distort a high type's design since this product doesn't concede information rents to any other type. Instead the problem is the residual demand curve of the high type is in the "wrong" position. ${ }^{23}$

The final point to emphasize is that welfare differences are more exaggerated than income differences. To see this, note a consumer's welfare is linear in product quality i.e. $U^{I}=n^{\frac{1}{\rho}} q^{I}$. Since product quality is above the first best for high types but below the first best for low types, it follows that differences in welfare outcomes must be more pronounced than income/endowment differences.

To underscore this last point and to help facilitate the analysis to come, consider the indirect utility function. A key step in deriving this function relates to the marginal shadow linear price for group $L$ :

$$
p^{L}=\theta^{L}\left(q^{L}\right)^{\rho-1}=\frac{\theta^{L}}{\theta^{H}}\left(\frac{q^{L}}{q^{H}}\right)^{\rho-1} \theta^{H}\left(q^{H}\right)^{\rho-1}=\frac{v}{\phi} w
$$

Indirect utility is then given by:

$$
\begin{aligned}
U^{L} & =n^{\frac{1}{\rho}}\left(\frac{\bar{m}^{L}}{n p^{L}}\right)=n^{\frac{1-\rho}{\rho}}\left(\frac{\bar{m}^{H}}{w}\right) \phi=\phi U^{H}, \\
U^{H} & =n^{\frac{1-\rho}{\rho}}\left(\frac{\rho\left(m^{H}-m^{L}\right)}{w\left(1-\phi^{\rho}\right)}\right) .
\end{aligned}
$$

${ }^{22}$ Recalling $\theta^{H}=\frac{\tilde{m}^{H}}{n\left(q^{H}\right)^{\rho}}$, the residual demand for the first best arises when $\tilde{m}^{H}=\rho m^{H}$. Using (13) it follows that $\frac{\bar{m}^{H}}{\rho m^{H}}=\frac{1-\eta}{1-\phi^{\rho}}>1$ from (14).

${ }^{23}$ Note this is not an artifact of the CES demand system. A similar result arises for the Melitz and Ottaviano (2008) demand system where it is the inability of firms to extract all rents under the residual demand curve that creates insufficient entry relative to the first best. Consequently, the residual demand faced by any firm is too large and the high income consumer is over-supplied. 
We are now in a position to reflect on the implications of firms using non-linear prices when the only source of variation across consumers is the income they possess. Apart from expanding a firm's strategy space in a plausible way, all of the other assumptions of the standard general equilibrium model of monopolistic competition are retained - especially the assumption of homothetic preferences and a constant elasticity of residual demand. Nevertheless the differences in product design and welfare outcomes are striking. A key take-away is that the distribution of income is the primary determinant of the size of distortions and consequently welfare outcomes. Given countries differ substantially in their income distributions, this suggests if we start from an autarky situation, the size and relevance of the distortions will also vary considerably across countries. How does trade affect these distortions? How do these distortions affect the gains from trade? It is to these questions we now turn our attention.

\section{Implications of International Trade}

\subsection{Free Trade in the Standard Model}

As a benchmark consider the standard model without trade costs where technology and preferences are as described above but firms are constrained to use linear prices. Since welfare of an income group is proportional to their income share we only need to consider aggregate demand for a variety and the number of varieties (which are a function of the relevant endowment, $n_{g}=\frac{L_{g}}{\sigma F}$; where $L_{g}$ is the size of the labor endowment of the integrated countries). Consequently, for a country with an endowment of $L_{i}$ that has access to $n_{g}$ varieties we have:

$$
q_{i}=\frac{p^{-\sigma} w L_{i}}{n_{g} p^{1-\sigma}}=\frac{\rho L_{i}}{n_{g}} \quad \Rightarrow \quad U_{i}=\rho n_{g}^{\frac{1}{\sigma-1}} L_{i}
$$

Autarky is then a situation where $n_{g}=n_{i}$ and free trade involves $n_{g}>n_{i}$. Using $\mathcal{F}$ to denote free trade and $\mathcal{A}$ for autarky it follows that the gains from trade in the standard 
model for country $i$ have the form:

$$
\frac{U_{i \mathcal{F}}}{U_{i \mathcal{A}}}=\left(\frac{L_{g}}{L_{i}}\right)^{\frac{1}{\sigma-1}}=\lambda_{i i}^{\frac{1}{1-\sigma}}
$$

where $\lambda_{i i}$ is the domestic expenditure share. Whenever this country engages in free trade with another country the sole mechanism for welfare change is through the number of varieties. This makes relative size the only determinant of the gains from free trade: the more varieties accessed under free trade, the larger the gains from free trade. In this setting differences in income distribution play no independent role.

\subsection{Free Trade with Implicit Discrimination}

Against this benchmark consider the integration of two countries with potentially different income distributions. As in the closed economy setting, assume that individuals have one of two endowments, $L^{L}$ or $L^{H}$. Then the only difference across countries is the fraction of high endowment types, $\beta_{i}$ where $i \in\{h, f\}$. In this environment free trade is interpreted as a situation where a firm cannot leverage knowledge of location. That is, product design based on the national income distribution isn't sustainable in equilibrium.

To see that segmentation isn't possible under free trade assume that the free trade equilibrium involves all firms using the global income distribution, $\beta_{g}$, to design products, $\phi_{g}$. Now ask: Can a firm profitably deviate and instead use the national distributions, $\left\{\beta_{h}, \beta_{f}\right\}$, to offer different designs in each market, $\left\{\phi_{h}, \phi_{f}\right\}$ ? To see that this isn't incentive compatible, observe that nominal income for each group is the same in both locations, $\left\{m^{L}, m^{H}\right\}$ along with the location of the residual demand functions, $\left\{\theta^{L}, \theta^{H}\right\}$. Since trade is free any consumer can potentially choose a product from the deviating firm in any country without paying an additional cost. Assume that $\beta_{h}>\beta_{f}$ which implies $\phi_{f}>\phi_{h}$. However, under the associated menu, a high income type in $h$ will treat the product offered to the low income consumer in $f$ as their outside option since it offers higher information rents. That is, $\frac{\theta^{H}\left(q_{h}^{H}\right)^{\rho}}{\rho}-T_{h}^{H}=\left(\theta^{H}-\theta^{L}\right) \frac{\left(q_{h}^{L}\right)^{\rho}}{\rho}<\frac{\theta^{H}\left(q_{f}^{L}\right)^{\rho}}{\rho}-T_{f}^{L}=\left(\theta^{H}-\theta^{L}\right) \frac{\left(q_{f}^{L}\right)^{\rho}}{\rho}$. This offering is not incentive compatible since the high income type in $h$ will purchase $\left\{q_{f}^{L}, T_{f}^{L}\right\}$ from this 
menu. Hence, under free trade, there must be a common global design, $\phi_{g} \cdot{ }^{24}$

The move from autarky to free trade then involves two changes for a country. The familiar one associated with an increase in variety and a second dimension involving changes in product design, $\phi_{i} \gtrless \phi_{g}$. As a consequence if countries have very different income distributions, then there will be very pronounced differences in product design across countries in autarky. So integration can potentially have a large impact on product design. To understand the implications of integration eliminating design variation across countries use (17), (18) and (19) to derive:

$$
G F T_{i}^{H}=\left(\frac{1-\phi_{i}^{\rho}}{1-\phi_{g}^{\rho}}\right) \lambda_{i i}^{\frac{1}{1-\sigma}} \quad \& \quad G F T_{i}^{L}=\left(\frac{\phi_{g}}{\phi_{i}}\right) G F T_{i}^{H}
$$

Using these expressions leads to the following claim.

PROPOSITION 2. If Home's per capita income is larger than Foreign's $\left(\beta_{h}>\beta_{f}\right)$, then Home's gains from free trade are greater than predicted by the standard model while the opposite holds in the Foreign country. Furthermore, within the Home country, the proportional gain follows a rank that is inversely related to income. Consequently, the lowest income group in the Home country gains the most from trade. The converse holds in the Foreign country.

Note that the global income distribution still involves two income classes but the fraction of high income types in the global economy, $\beta_{g}$, is greater than $\beta_{f}$ but less than $\beta_{h}$. The first part of Proposition 2 follows immediately from (15), which gives the following rank: $\phi_{f}>$ $\phi_{g}>\phi_{h}$. The second part of proposition 2, the rank within countries, follows immediately from (20).

This proposition reveals that the gains from trade are fundamentally changed by SDPD. In the standard model, relative size is the sole determinant of the gains from trade: the smaller the country, the larger the gains from trade. In our two type model, this implies the country with the lower average income would gain the most from trade. With SDPD, relative size is no longer enough to completely characterize the gains from trade. In fact a smaller country may have their variety gains from trade dramatically diminished by inferior

\footnotetext{
${ }^{24} \mathrm{An}$ interesting issue about intellectual property rights (IPR) arises in this context. In particular, we have implicitly assumed markets cannot be segmented internationally by IPR. While it is not explored in this paper, the results below suggests a country's preferences over IPR regime will vary with country income and also the level of trade barriers.
} 
product design. The main mechanism operates through the desire of firms to customize products to income classes to extract rents - better products generate more surplus but also concede information rents to higher income groups. This trade-off is resolved with reference to the distribution of income. The critical factor shaping the gains from trade is then the extent and nature of the difference between the national and global income distributions. Pronounced differences give rise to big differences not just between the number of varieties available but also between the menu of choices offered in autarky and free trade.

\subsection{Trade Costs and the Gains from Trade}

The gains from trade identified above have two components. The familiar variety gains and a new dimension due to product design. This section considers how the level of trade costs interacts with each of these components. As we'll see, variety gains increase monotonically when trade barriers are lowered. In contrast, product design changes are only induced at relatively low trade costs. Intuitively, high trade costs allow firms to treat each country in isolation, offering a menu tailored to the characteristics of each location. However, once trade barriers become sufficiently low, these design differences generate an incentive for international arbitrage within a firm's product line; with the offerings across countries becoming more similar as trade barriers fall further.

To gain insight into the mechanism, once again assume $\beta_{h}>\beta_{f}$. Under segmented markets this implies $\phi_{f}>\phi_{h}$. Consequently, if trade costs are low enough, consumers in the Home country have an incentive to pay the transport costs of purchasing from the product line in the foreign country. How do firms respond to these incentives and what are the implications for product line design and welfare? It is to this question we now turn.

We follow convention and assume that trade costs take an iceberg form: $\tau>1$ is shipped for one unit to arrive overseas. To clarify the motive for international arbitrage, consider the instance where it is strongest: Home high type with respect to the Foreign low type product within a Foreign firm's product line. The incentive constraint in this case can be written as:

$$
\theta_{h}^{H} \frac{\left(q_{h f}^{H}\right)^{\rho}}{\rho}-T_{h f}^{H}=\max \left\{\theta_{h}^{H} \frac{\left(q_{h f}^{L}\right)^{\rho}}{\rho}-T_{h f}^{L}, \theta_{h}^{H} \frac{\left(q_{f f}^{L}\right)^{\rho}}{\rho \tau^{\rho}}-T_{f f}^{L}\right\}
$$


If $\tau$ is large, then $\theta_{h}^{H} \frac{\left(q_{h f}^{L}\right)^{\rho}}{\rho}-T_{h f}^{L}>\theta_{h}^{H} \frac{\left(q_{f f}^{L}\right)^{\rho}}{\rho \tau^{\rho}}-T_{f f}^{L}$. In this case the incentive constraints are national in nature. However, it is also possible that if a firm attempts to treat markets as segmented when $\tau$ is small then $\theta_{h}^{H} \frac{\left(q_{h f}^{L}\right)^{\rho}}{\rho}-T_{h f}^{L}<\theta_{h}^{H} \frac{\left(q_{f f}^{L}\right)^{\rho}}{\rho \tau^{\rho}}-T_{f f}^{L}$; Home high types have a strict incentive to purchase $q_{f f}^{L}$. Since such cross-hauling isn't optimal, the foreign firm will concede additional information rents to the Home high types (i.e. improve relative design in the Home market). Using the constraint that the information rents for Home high must be equalized across locations, $\theta_{h}^{H} \frac{\left(q_{h f}^{L}\right)^{\rho}}{\rho}-T_{h f}^{L}=\theta_{h}^{H} \frac{\left(q_{f f}^{L}\right)^{\rho}}{\rho \tau^{\rho}}-T_{f f}^{L}$, implies:

$$
q_{h f}^{L}=\chi^{\frac{1}{\rho}} q_{f f}^{L} \quad \text { where } \chi=\frac{\left(\theta_{h}^{H} / \tau^{\rho}-\theta_{f}^{L}\right)}{\left(\theta_{h}^{H}-\theta_{h}^{L}\right)}
$$

To see the implications of different levels of trade costs, consider the profit function for a foreign firm:

$$
\begin{aligned}
\pi_{f}=\beta_{h}\left(T_{h f}^{H}-w_{f} \tau q_{h f}^{H}\right) & +\left(1-\beta_{h}\right)\left(T_{h f}^{L}-w_{f} \tau q_{h f}^{L}\right) \\
& +\beta_{f}\left(T_{f f}^{H}-w_{f} q_{f f}^{H}\right)+\left(1-\beta_{f}\right)\left(T_{f f}^{L}-w_{f} q_{f f}^{L}\right)-w_{f} F
\end{aligned}
$$

subject to

$$
\begin{aligned}
& \theta_{h}^{H} \frac{\left(q_{h f}^{H}\right)^{\rho}}{\rho}-T_{h f}^{H}=\max \left\{\theta_{h}^{H} \frac{\left(q_{h f}^{L}\right)^{\rho}}{\rho}-T_{h f}^{L}, \theta_{h}^{H} \frac{\left(q_{f f}^{L}\right)^{\rho}}{\rho \tau^{\rho}}-T_{f f}^{L}\right\} \& \quad \theta_{h}^{L} \frac{\left(q_{h f}^{L}\right)^{\rho}}{\rho}-T_{h f}^{L}=0, \\
& \theta_{f}^{H} \frac{\left(q_{f f}^{H}\right)^{\rho}}{\rho}-T_{f f}^{H}=\max \left\{\theta_{f}^{H} \frac{\left(q_{f f}^{L}\right)^{\rho}}{\rho}-T_{f f}^{L}, \theta_{f}^{H} \frac{\left(q_{h f}^{L}\right)^{\rho}}{\rho \tau^{\rho}}-T_{h f}^{L}\right\} \& \quad \theta_{f}^{L} \frac{\left(q_{f f}^{L}\right)^{\rho}}{\rho}-T_{f f}^{L}=0,
\end{aligned}
$$

For large $\tau$, the first term in each of the $\max$ functions is the largest, consequently the incentive constraints are national in scope. In this case, a firm can optimize each market independently and will adopt autarkic designs for each market - there will be variation in design across countries but not within countries across firms. ${ }^{25}$ To gain insight into the implications of international arbitrage, consider a small $\tau$ setting such that (21) holds. Substituting and collecting terms gives the following objective function for a low trade cost

\footnotetext{
${ }^{25}$ See the proof of Proposition 3 for details.
} 
environment:

$$
\begin{aligned}
\pi_{f}= & \beta_{h}\left(\theta_{h}^{H} \frac{\left(q_{h f}^{H}\right)^{\rho}}{\rho}-w_{f} \tau q_{h f}^{H}\right)+\beta_{f}\left(\theta_{f}^{H} \frac{\left(q_{f f}^{H}\right)^{\rho}}{\rho}-w_{f} q_{f f}^{H}\right) \\
& +\left(\left(\left(\theta_{h}^{L}-\beta_{h} \theta_{h}^{H}\right) \chi+\left(\theta_{f}^{L}-\beta_{f} \theta_{f}^{H}\right)\right) \frac{\left(q_{f f}^{L}\right)^{\rho}}{\rho}-\left(\left(1-\beta_{f}\right)+\left(1-\beta_{h}\right) \tau \chi^{\frac{1}{\rho}}\right) w_{f} q_{f f}^{L}\right)-w_{f} F
\end{aligned}
$$

Profit maximization requires:

$$
\begin{aligned}
& \frac{\partial \pi_{f}}{\partial q_{h f}^{H}}=\theta_{h}^{H}\left(q_{h f}^{H}\right)^{\rho-1}-\tau w_{f}=0 \\
& \frac{\partial \pi_{f}}{\partial q_{f f}^{H}}=\theta_{f}^{H}\left(q_{f f}^{H}\right)^{\rho-1}-w_{f}=0 \\
& \frac{\partial \pi_{f}}{\partial q_{f f}^{L}}=\left(\left(\theta_{h}^{L}-\beta_{h} \theta_{h}^{H}\right) \chi+\left(\theta_{f}^{L}-\beta_{f} \theta_{f}^{H}\right)\right)\left(q_{f f}^{L}\right)^{\rho-1}=\left(\left(1-\beta_{f}\right)+\left(1-\beta_{h}\right) \tau \chi^{\frac{1}{\rho}}\right) w_{f}
\end{aligned}
$$

If we define $\phi_{i j}=\left(q_{i j}^{L} / q_{i j}^{H}\right)$ as the relative design by a firm in $j$ for market $i$, then these conditions imply:

$$
\left(\left(\theta_{h}^{L}-\beta_{h} \theta_{h}^{H}\right) \chi+\left(\theta_{f}^{L}-\beta_{f} \theta_{f}^{H}\right)\right)\left(\phi_{f f}\right)^{\rho-1}=\left(\left(1-\beta_{f}\right)+\left(1-\beta_{h}\right) \tau \chi^{\frac{1}{\rho}}\right) \theta_{f}^{H}
$$

This condition defines the relative design for a foreign firm that is constrained by international arbitrage - that is (21) binds to impose an additional constraint on the firm optimization problem. Let the highest $\tau$ where (21) binds be denoted by $\bar{\tau}$.

Similar arguments apply when the international arbitrage constraint binds within a Home firm's product line. However, this occurs for a trade cost strictly below $\bar{\tau}$. Even so, the international arbitrage constraint takes a similar form where $q_{h h}^{L}=\chi^{\frac{1}{\rho}} q_{f h}^{L}$ and the relative design for the foreign market by a Home firm, $\phi_{f h}=\left(q_{f h}^{L} / q_{f h}^{H}\right)$, is derived to be:

$$
\left(\left(\theta_{h}^{L}-\beta_{h} \theta_{h}^{H}\right) \chi+\left(\theta_{f}^{L}-\beta_{f} \theta_{f}^{H}\right)\right)\left(\phi_{f h}\right)^{\rho-1}=\left(\left(1-\beta_{f}\right)+\left(1-\beta_{h}\right) \chi^{\frac{1}{\rho}} / \tau\right) \theta_{f}^{H}
$$

We can now see how relative design behaves when international arbitrage constraints bind. First, the design in the Home market improves while design in the Foreign market is 
made worse. This follows from the incentive constraints - the motive for international arbitrage is removed by both increasing the information rents in the product lines offered in the Home market and reducing information rents available in the Foreign market. Nevertheless, differences in product designs will persist across markets until markets are completely integrated. Moreover, there will be differences in design within markets across firms. Using (22) and (23) it follows that $\phi_{f h}>\phi_{f f}$, which in turn implies $\phi_{h h}>\phi_{h f}$. This discussion makes it clear that if trade costs are high, then markets are treated as segmented by firms and menu's are designed based on national characteristics. However, beyond some level of trade costs, $\bar{\tau}$, this behavior cannot be sustained and the potential for international arbitrage influences design. In short, relative design is only responsive to trade costs when trade barriers are relatively low.

In the standard model, lower iceberg trade costs lead to higher welfare for all countries. ${ }^{26}$ While it is tempting to assume that a similar monotonicity applies in the SDPD model, the following proposition reveals that all of the differences from the standard model arise only once trade barriers are sufficiently low.

PROPOSITION 3. Let $\tau \geq 1$ represent the iceberg transport cost between the Home and the Foreign country. Then there exists a transport cost $\bar{\tau}$ such that the gains from trade for a high income type are:

$$
\operatorname{GFT}_{i}^{H}(\tau)= \begin{cases}\lambda_{i i}^{\frac{1}{1-\sigma}} & \text { for } \tau \geq \bar{\tau} \\ \left(\frac{1-\phi_{i}^{\rho}}{1-\bar{\phi}_{i \tau}^{\rho}}\right) \lambda_{i i}^{\frac{1}{1-\sigma}} & \text { for } \tau<\bar{\tau}\end{cases}
$$

and for the low income type

$$
\operatorname{GFT}_{i}^{L}(\tau)= \begin{cases}\lambda_{i i}^{\frac{1}{1-\sigma}} & \text { for } \tau \geq \bar{\tau} \\ \left(\frac{\bar{\phi}_{i \tau}}{\phi_{i}}\right) \operatorname{GFT}_{i}^{H}(\tau) & \text { for } \tau<\bar{\tau}\end{cases}
$$

where $d_{i j}=\left(\frac{\tau w_{j}}{w_{i}}\right)^{1-\sigma}$ and $\lambda_{i i}=\frac{L_{i}}{L_{i}+d_{i j} L_{j}}$ denotes the domestic expenditure share, $\bar{\phi}_{i \tau}=\left(\frac{n_{i}}{\tilde{n}_{i}} \phi_{i i}^{\rho}+\frac{d_{i j} n_{j}}{\tilde{n}_{i}} \phi_{i j}^{\rho}\right)^{\frac{1}{\rho}}$ is the average product design in i for trade cost $\tau$ where $\tilde{n}_{i}=\sum_{j} n_{j} d_{i j}$ and $\phi_{i}$ is product design under

\footnotetext{
${ }^{26}$ The absence of tariff revenue implies the optimal trade cost is zero for all countries. For an analysis of trade policy with general pricing behavior see Antràs and Staiger (2012) and McCalman (2010).
} 
autarky/segmentation. ${ }^{27}$

This says that when trade barriers are high, the SDPD model delivers the same proportional gains from trade as the standard model. ${ }^{28}$ Thus, all the changes described in Proposition 2 occur only after trade barriers are below $\bar{\tau} .{ }^{29}$

This interaction between trade barriers and welfare highlights a potential downside to incremental trade liberalization: beyond a point one country simply may not benefit from further trade liberalization. Once again the root cause is differences across countries in the distribution of income and the associated design of products. When markets are segmented, access to additional varieties is the only source of gains from trade. As trade barriers fall, markets become more deeply integrated and product design becomes more universal. As we have seen, this standardizing of menus doesn't bring unambiguous gains to all consumers in all countries. Understanding the potential magnitude of this mechanism motivates the quantification exercise of section $4 .^{30}$

\subsection{Trade Flows and Similarity of Income Distribution}

The potential for welfare outcomes to vary dramatically from the standard model raises the question of whether there is a similarly pronounced analog for an observable outcome like trade flows. To explore this issue we extend the model to a setting where the number of countries is greater than two but we retain the assumption of two consumer types within a country. To allow for the possibility that markets are segmented, partially integrated or that this status varies by trading partner, we write the prices set by firms in $j$ for consumers in $i$ as:

$$
T_{i j}^{H}=d_{i j} \frac{\bar{m}_{i}^{H}}{\rho \tilde{n}_{i}}\left(1-\phi_{i j}^{\rho}\right)+T_{i j}^{L}, \quad T_{i j}^{L}=d_{i j} \frac{\bar{m}_{i}^{L}}{\rho \tilde{n}_{i}} \frac{\phi_{i j}^{\rho}}{\bar{\phi}_{i}^{\rho}} .
$$

\footnotetext{
${ }^{27}$ For the subscript $i, j$, the first subscript indicates the locations of consumption ( $i=$ importer) and the second subscript, $j$, indexes the location of production.

${ }^{28}$ Such a $\bar{\tau}$ also exists in a model of SDPD based on the Melitz and Ottaviano (2008) demand system. See McCalman (2016a).

${ }^{29}$ Thomas (2011) documents country specific product line design in the context of washing powder even when production for multiple countries is concentrated in a single plant. For a study of the interaction between product features, trade costs and FDI, see McCalman and Spearot (2013).

${ }^{30} \mathrm{~A}$ number of other extensions are possible including adding a second sector to consider home market effects and a second factor to consider factor price implications. Additionally, a retail sector can be included to capture the implications of product design for global value chains. These extensions are set-out in McCalman (2016b).
} 
where $\bar{\phi}_{i}=\left(\sum_{j} \frac{d_{i j} n_{j}}{\tilde{n}_{i}} \phi_{i j}^{\rho}\right)^{\frac{1}{\rho}}, \tilde{n}_{i}=\sum_{j} n_{j} d_{i j}$ and $d_{i j}=\left(\frac{\tau_{i j} w_{j}}{w_{i}}\right)^{1-\sigma}$. This definition of the average design in market $i$ now incorporates a multi-country dimension, where countries can differ in terms of trade costs, $\tau_{i j}$, and the design they make available in $i, \phi_{i j}$. Bilateral trade between importer $i$ and exporter $j$ is then shaped by these two forces:

$$
X_{i j}=n_{j}\left(\beta_{i} T_{i j}^{H}+\left(1-\beta_{i}\right) T_{i j}^{L}\right)=\frac{n_{j} d_{i j}}{\tilde{n}_{i}} \frac{\bar{m}_{i}^{H}}{\rho}\left(\beta_{i}+\left(v_{i}-\beta_{i} \bar{\phi}_{i}^{\rho}\right)\left(\frac{\phi_{i j}}{\bar{\phi}_{i}}\right)^{\rho}\right) .
$$

In addition, note that aggregate trade is balanced:

$$
\beta_{i} m_{i}^{H}+\left(1-\beta_{i}\right) m_{i}^{L}=X_{i}=\sum_{j} X_{i j}=\frac{\bar{m}_{i}^{H}}{\rho}\left(\beta_{i}+\left(v_{i}-\beta_{i} \bar{\phi}_{i}^{\rho}\right)\right) .
$$

This implies the following expenditure shares for country $i$ :

$$
\frac{X_{i j}}{X_{i}}=s_{i j}\left(\frac{\beta_{i}+\left(v_{i}-\beta_{i} \bar{\phi}_{i}^{\rho}\right)\left(\frac{\phi_{i j}}{\bar{\phi}_{i}}\right)^{\rho}}{\beta_{i}+\left(v_{i}-\beta_{i} \bar{\phi}_{i}^{\rho}\right)}\right) \quad \text { where } \quad s_{i j}=\frac{n_{j} d_{i j}}{\sum n_{k} d_{i k}}
$$

Since $s_{i j}$ captures the gravity equation from the standard model it is apparent that trade flows will deviate from this to the extent that products from country $j$ diverge from the typical designs consumed in country $i, \frac{\phi_{i j}}{\bar{\phi}_{i}}$, and, if so, on the sign of $\left(v_{i}-\beta_{i} \bar{\phi}_{i}^{\rho}\right)$. The interaction of these components determine whether trade is above or below that predicted by $s_{i j}$. The behavior of these terms is especially clear in a world composed of countries that have extreme income differences: $\beta_{i} \in\{0,1\}$.

To gain additional insight consider a many country setting where there are $N$ countries with $\beta_{i}=0$ and $N$ others with $\beta_{i}=1$, all of which are equidistant apart $\left(\tau_{i j}=\tau\right)$, but sufficiently close for country pairs to be partially integrated $(\tau<\bar{\tau})$. For importers where $\beta_{i}=0$ the expenditure shares are simply $s_{i j}\left(\frac{\phi_{i j}}{\bar{\phi}_{i}}\right)^{\rho}$. If the product design from country $j$ is above the average in country $i$, then trade exceeds the standard gravity benchmark. Conversely, if exporter $j$ offers a design below the average in $i$, trade shares are lower than predicted by the standard gravity model. The following lemma links product design to exporter per capita income in this setting:

LEMMA 1. If $\beta_{j}=0$ then $\phi_{i j}>\bar{\phi}_{i} \forall i$. If $\beta_{j}=1$ then $\phi_{i j}<\bar{\phi}_{i} \forall i$. 
This lemma says that in a model where firms choose product design, exporters with low per capita income export products that are tailored toward low income consumers relative to the exports of high income countries. Consequently, the expenditure share of a low per capita income country on exports from a low per capita income partner will be greater than the standard gravity prediction, while the opposite holds for the expenditure share of exports from a high per capita income country.

In contrast, when $\beta_{i}=1$ the trade shares are given by $s_{i j}\left(\frac{1+\left(v_{i}-\bar{\phi}_{i}^{\rho}\right)\left(\frac{\phi_{i j}}{\bar{\phi}_{i}}\right)^{\rho}}{1+\left(v_{i}-\bar{\phi}_{i}^{\rho}\right)}\right)$. Observing that $v_{i}-\bar{\phi}_{i}^{\rho}<0$ and using Lemma 1 , it follows immediately that a country with a high per capita income imports more from a high per capita income trading partner than predicted by the benchmark gravity equation and less from a low per capita income exporter.

Moreover, the pattern of trade predicted when the $\beta_{i} \in\{0,1\}$ also holds for income differences that are less extreme (i.e. $\beta_{i} \in[0,1]$ ). This provides us with the following proposition

PROPOSITION 4. If countries differ in per capita income and trade barriers are low enough for markets to be partially integrated, the SDPD model predicts that the deviation from the standard gravity model can be either positive or negative. More trade is predicted if the difference in GDP per capita is not too large. However, if the difference is relatively large, then the SDPD model predicts lower trade volumes than the standard gravity model.

This result resembles the "Linder Hypothesis" in that it relates the volume of trade to differences in per-capita income: similarity in per capita income gives rise to augmented trade flows but large differences reduce the volume of trade. To date it has been asserted that such a trade pattern can only be explained by non-homothetic preferences. What is interesting about the above result is that preferences are not only identical and homothetic, but they also impose the additional restriction that the elasticity of demand is constant. Nevertheless, simply allowing firms to maximize profits by exploiting information on income distribution through product design results in a positive correlation between similarity in income per-capita and trade. While there is variation across consumers on the demand-side, it is purely in terms of income rather than hardwired into preferences.

The intuition is also straightforward. When markets are partially integrated, a location 
that delivers a product design better than the average faces two competing forces that shape trade flows. First, an above average design allows more rents to be extracted from the low types simply because a better product generates more rents. Second, a better product design allows the higher income types to capture more information rents, which tends to suppress the volume of trade by lowering prices for the higher income types. When the importing country has a low per capita income, the first effect dominates and trade flows are higher than predicted by the standard gravity equation. However, when the importer is high income per capita, the second effect dominates and trade flows tend to be smaller than the standard model would predict. The fact that low income exporters tend to offer products more suited to low income types (i.e. better designs in our terminology) this then generates the pattern predicted in Proposition 4.

\section{Quantifying the Gains from Integration}

The key insight of Proposition 3 is that trade barriers can be partitioned into two sets. High trade barriers that allow firms to segment markets internationally with design based on national income distributions. At these high levels, marginal changes in trade barriers do not change relative design - any gains from trade reflect the mechanisms summarized by ACR. However, at low trade barriers complete segmentation isn't possible - changes in trade barriers continue to generate ACR style gains but now relative designs also change (see (24) and (25)), generating a second dimension to the welfare analysis. The natural question is whether this new component is quantitatively significant.

Any attempt to quantify the importance of implicit discrimination needs to account for three unobserved elements of the model. First, in common with the ACR framework, the full integration outcome is not observed in the data. This explains why ACR focus on comparing an observed outcome $\left(\lambda_{i i}\right)$ with the well defined counterfactual benchmark of autarky $(\lambda=1)$. Second, how do you determine whether an observed outcome corresponds to segmentation or partial integration? Third, even conditional on answering the second question, product designs are typically not observable.

As a starting point to address these questions we are guided by a desire to make the comparison with ACR/CRC as close as possible. That is, we want to discipline the analysis 
so that both models have the same welfare prediction in the base year, 2008. For the ACR model this only requires knowledge of the domestic expenditure share, $\lambda_{i i}$, and the trade elasticity, $\sigma-1$. To get the same welfare prediction from the SDPD model requires that all markets are internationally segmented $(\tau>\bar{\tau})$. Hence, the desire for a point of overlap between the two approaches then provides an answer to the second question (an alternative is also explored below). The answer to the third question, product designs, utilizes the equilibrium conditions to impute designs based on national and global income distributions, along with the trade elasticity. These conditions and data are set out below, and they allow us to calculate implied values for designs under segmentation and also under full integration.

This still leaves the issue of the counterfactual value of the domestic expenditure share under full integration, $\lambda_{i i}^{I n t}$. Rather than taking a stand on an explicit value for each country, we invert the process based on the differences in designs under segmentation and integration. In particular, given that product design changes can be negative for some income classes in some countries, we find it more instructive to ask, "what change in domestic expenditure share is necessary for all income groups in $i$ to gain from complete integration?". If the required changes in domestic expenditure are relatively small, then it seems legitimate to conclude that design changes only have a small impact on the gains from trade. On the other hand, if the required changes are large this goes someway to suggesting that design changes may have some role to play. An important caveat to bear in mind is that the assumption of initially segmented markets tends to produce conditions where the impact of design changes are most pronounced. This suggests the results are more accurately interpreted as an upper bound on the role for changes in product design.

To begin the analysis recall that the ARC measure calculates the gains that move from an initial trading equilibrium with $\lambda_{i i}$ to one of full integration characterized by $\lambda_{i i}^{I n t}$ to be $\widehat{W}_{i}=\left(\frac{\lambda_{i i}^{I n t}}{\lambda_{i i}}\right)^{\frac{1}{1-\sigma}}=\hat{\lambda}_{i i}^{\frac{1}{1-\sigma}}$. The SDPD model says that design changes induced by additional integration can modify this prediction. To keep track of designs across outcomes the notation is generalized in the following way. To allow for additional income groups within a country, index each income group by $I \in[1, \ldots . ., \bar{I}]$ where $\bar{I}$ is the maximum income. Design for group $I$ is then measured relative to that of $\bar{I}, \phi_{i}^{I}=q_{i j}^{I} / q_{i j}^{\bar{I}}$ in country $i$. In the analy- 
sis that follows the reference group is always $\bar{I}$. The subscript $i$ on relative design is only needed for the segmented outcome. When markets are integrated, design is based on the global income distribution and is common across countries, $\phi^{I}$.

To match the multi-country setting of CRC we generalize the formulas from Proposition 3 for income groups $I \in[1, \ldots . ., \bar{I}]: 31$

$$
\widehat{W}_{i}^{\bar{I}}=\left(A d j^{\bar{I}}\right) \hat{\lambda}_{i i}^{\frac{1}{1-\sigma}}, \quad \widehat{W}_{i}^{I}=\left(A d j^{I}\right) \hat{\lambda}_{i i}^{\frac{1}{1-\sigma}} \text { when } I \neq \bar{I}
$$

and where $A d j^{\bar{I}}=\left(\frac{1-\left(\phi_{i}^{k}\right)^{\rho}}{1-\left(\phi^{k}\right)^{\rho}}\right), A d j^{I}=A d j^{\bar{I}}\left(\frac{\phi^{I}}{\phi_{i}^{I}}\right), k=\bar{I}-1$ and a subscript $i$ on $\phi$ implies a design based on the trade cost vector $\tau \in\{\bar{\tau}, \infty\}$. The adjustment factors, $\operatorname{Adj}^{\bar{I}} \lessgtr 1$ and $A d j^{I} \lessgtr 1$, capture the impact of design changes relative to the ACR framework. Since the counterfactual is one that goes from segmentation to full integration, these adjustment factors typically will not equal 1 . The main task is to derive the product designs under segmentation, $\phi_{i}^{I}$, and integration, $\phi^{I}$. The magnitude of these design differences will determine whether or not the adjustment factors deviate significantly from unity.

Calculation of these design changes requires information on the distribution of income and the elasticity $\sigma$. Following CRC we set $\sigma=6$. Information on the income distribution for a large number of countries is compiled by Lakner and Milanovic (2015). These data have the virtue that they are constructed for the purpose of international comparison and also to facilitate the derivation of the global distribution of income. The global income distribution is broken into five bins, each with the same total income. The global population distribution for each quintile is given in Table 1.

Table 1

Global Income Distribution 2008

\begin{tabular}{cccccc}
\hline & Q1 & Q2 & Q3 & Q4 & Q5 \\
Population Share & 74 & 13 & 7 & 4 & 2 \\
\hline
\end{tabular}

Under full integration a firm designs products based on the global income distribution. However, under segmented markets firms use the local distribution. This is derived as the fraction of the national population which falls into each bin. Such a formulation ensures

\footnotetext{
${ }^{31}$ See the appendix for the derivation.
} 
that the national income distributions aggregate to the global distribution. ${ }^{32}$ With income distributions in hand, we can derive the equilibrium set of designs by solving the following equations that apply in the many income class setting: ${ }^{33}$

$$
\frac{P_{i}\left[m>m^{I}\right]}{P_{i}\left[m \geq m^{I}\right]}\left(\frac{v^{J}}{\left(\phi_{i}^{J}\right)^{\rho}}\right)\left(\phi_{i}^{I}\right)^{\rho}+\frac{\beta_{i}^{I}}{P_{i}\left[m \geq m^{I}\right]} \phi_{i}^{I}=v^{I}
$$

where $v^{I}=\bar{m}^{I} / \bar{m}^{\bar{I}}, J \equiv \min \{I+1, \bar{I}\}$ and $P_{i}\left[m>m^{I}\right]=\sum_{I+1}^{\bar{I}} \beta_{i}^{I}$ is the fraction of the relevant population (national or global) with income strictly greater than $m^{I}\left(P_{i}\left[m \geq m^{I}\right]\right.$ is defined similarly).

Under segmentation, the relevant distribution is the national distribution, so (29) is solved for each of the 33 countries in the sample based on their unique income distributions. Under full integration, design is based on the global income distribution - the same menu is offered to all countries. Hence, the difference between the segmented and the integrated equilibrium is determined exclusively by the difference between the national and global income distribution.

Table 2 presents the adjustment factors defined by (28) utilizing the designs implied by (29) for the set of countries analyzed by CRC. Columns (1)-(5) are the adjustment factors for each income quintile, $A d j^{I}$, when moving from segmentation to full integration in each country. A void implies that a country has no mass in that part of the distribution. These factors suggest that by omitting design considerations the USA is likely to have its gains from integration understated the most by the ACR measure. In particular, the lowest income group will have gains up to $\frac{1}{3}$ higher if design considerations are included in welfare calculations. In fact, every income group in the USA is predicted to have gains from integration augmented by design improvements. However, this is a relatively uncommon outcome, with only four other countries having all income groups gain unambiguously from beneficial design changes. The majority of countries have at least one income group that is subject to the negative consequences of design change - for many this also applies to the majority of the population.

To help put these adjustments into context, column (6) lists domestic expenditure share

\footnotetext{
${ }^{32}$ We follow Fajgelbaum and Khandelwal (2015) and assume that the extent of integration doesn't alter the income distribution.

${ }^{33}$ See appendix for details.
} 
required for all income groups to unambiguously gain from integration - this expenditure share generates the minimum ACR gains required to ensure every income group gains. Specifically, if $A d j^{I}<1$, then solve for the $\lambda$ that generates $\hat{W}^{I}=1$, that is $\bar{\lambda}_{i i}^{\text {Int }}=\max \left\{\left(A d j_{i}^{I}\right)^{\sigma-1} \lambda_{i i}\right\}, I \in\{1, . ., 5\}$. If full integration occurs before this expenditure share is achieved then at least one income group in country $i$ will be better off in the initial trading equilibrium. To provide context column (7) reports $\lambda_{i i}$, so the difference between column (6) and (7) is the change in domestic expenditure required for all consumer groups in country $i$ to gain - see column (8). For some countries the reduction in domestic expenditure share is relatively small and it is plausible that no income group in these countries would be adversely affected by further integration. These tend to be either relatively rich and/or open economies. However, for other countries this gap is daunting, with 12 countries facing at least a 10 percentage point decline in domestic expenditure share before the traditional gains from trade are sufficient to offset the design consequences of integration.

A sense of the scale of adjustment required is given by the change in the domestic share for each country over the period 1995-2008 - see column (9). This also offers the potential for an alternative interpretation. Suppose, in contrast to the maintained assumption, that 2008 reflects a fully integrated equilibrium; for 2008 design is based on the global income distribution and $\lambda_{i i}$ is the full integration domestic expenditure share. Assuming that 1995 represents a segmented equilibrium then the adjustment factors account for the implied design changes between 1995 and 2008. ${ }^{34}$ Under this interpretation whenever (9) $>$ (8), it would be the case that all income groups gain from integration. However, for 18 countries this condition fails. Consequently, both sets of assumptions suggest that design considerations have the potential to appreciably alter the gains from trade liberalization.

\section{Conclusion}

This paper considers the implications of allowing firms to be sophisticated enough to design product lines. Such a level of sophistication makes them interested in consumer level information, and the distribution of income in particular. Enriching firm behavior in this way results in a tractable model and provides a link between the distribution of income and

\footnotetext{
${ }^{34}$ Holding income distribution constant.
} 
the gains from trade.

This link arises as firms implicitly discriminate between the various income classes, which in equilibrium results in a product line that differs from what a utilitarian social planner would choose. Since the distortions are largest at the lower end of the income distribution, this is where the consequences of international integration are also most pronounced. Trade can reduce these distortions in countries whose income distributions dominate the global distribution, while amplifying them in countries that are dominated.

This structure implies the impact of integration is even more pronounced under a process of gradual liberalization since the variety and design dimensions of welfare respond differentially to the level of trade barriers. In particular, design changes occur disproportionately at lower trade barriers, with the potential to derail the process of trade liberalization. Quantifying the relative importance of this mechanism suggests that it is a legitimate issue that could significantly complicate future integration efforts. 
Table 2

Modified Welfare Outcomes from Trade Liberalization

\begin{tabular}{|c|c|c|c|c|c|c|c|c|c|}
\hline & (1) & (2) & (3) & (4) & (5) & (6) & (7) & (8) & (9) \\
\hline & $A d j_{1}$ & $A d j_{2}$ & $\mathrm{Adj}_{3}$ & $\mathrm{Adj}_{4}$ & $A d j_{5}$ & $\bar{\lambda}_{i i}^{I n t}$ & $\lambda_{i i}$ & $\Delta \bar{\lambda}_{i i}^{I n t}$ & $\left.\Delta \lambda_{i i}\right|_{c} ^{(}$ \\
\hline AUS & 1.21 & 1.05 & 1.02 & 0.99 & & 0.86 & 0.89 & 0.02 & 0.02 \\
\hline AUT & 1.23 & 1.06 & 1.02 & 1.00 & & 0.73 & 0.75 & 0.02 & 0.06 \\
\hline BEL & 1.20 & 1.04 & 1.00 & 0.98 & & 0.63 & 0.68 & 0.05 & 0.04 \\
\hline BRA & 0.98 & 0.98 & 0.97 & & & 0.80 & 0.93 & 0.12 & 0.02 \\
\hline CAN & 1.31 & 1.14 & 1.09 & 1.04 & 1.02 & & 0.83 & & 0.01 \\
\hline $\mathrm{CHN}$ & 0.95 & 0.95 & & & & 0.66 & 0.87 & 0.21 & 0.05 \\
\hline $\mathrm{CZE}$ & 1.08 & 0.98 & 0.97 & & & 0.63 & 0.73 & 0.10 & 0.06 \\
\hline DEU & 1.24 & 1.08 & 1.04 & 1.03 & 1.02 & & 0.80 & & 0.08 \\
\hline DNK & & 1.06 & 1.02 & 1.00 & & 0.73 & 0.74 & 0.02 & 0.07 \\
\hline ESP & 1.16 & 1.02 & 1.00 & 0.98 & & 0.78 & 0.85 & 0.07 & 0.04 \\
\hline FIN & 1.20 & 1.04 & 1.00 & 0.98 & & 0.74 & 0.80 & 0.06 & 0.05 \\
\hline FRA & 1.24 & 1.08 & 1.04 & 1.03 & 1.02 & & 0.86 & & 0.03 \\
\hline GBR & 1.30 & 1.13 & 1.08 & 1.04 & 1.02 & & 0.85 & & 0.01 \\
\hline GRC & 1.12 & 1.01 & 1.00 & 0.98 & & 0.73 & 0.81 & 0.07 & 0.08 \\
\hline HUN & 0.99 & 0.95 & & & & 0.50 & 0.66 & 0.16 & 0.15 \\
\hline IDN & 0.93 & & & & & 0.58 & 0.86 & 0.28 & 0.02 \\
\hline IND & 0.93 & & & & & 0.60 & 0.89 & 0.29 & 0.05 \\
\hline IRL & 1.21 & 1.05 & 1.02 & 0.99 & & 0.64 & 0.66 & 0.02 & 0.04 \\
\hline ITA & 1.20 & 1.04 & 1.00 & 0.98 & & 0.80 & 0.86 & 0.07 & 0.03 \\
\hline JPN & 1.17 & 1.04 & 1.00 & 0.98 & & 0.85 & 0.92 & 0.07 & 0.04 \\
\hline KOR & 1.19 & 1.05 & 1.02 & 0.99 & & 0.78 & 0.80 & 0.02 & 0.07 \\
\hline MEX & 0.98 & 0.98 & 0.97 & & & 0.73 & 0.85 & 0.11 & 0.02 \\
\hline NLD & & 1.08 & 1.03 & 1.00 & & 0.72 & 0.73 & 0.01 & 0.03 \\
\hline POL & 0.99 & 0.95 & & & & 0.61 & 0.80 & 0.19 & 0.09 \\
\hline PRT & 1.08 & 0.99 & & 0.99 & & 0.75 & 0.80 & 0.05 & 0.04 \\
\hline ROM & 0.95 & 0.95 & & & & 0.60 & 0.80 & 0.19 & 0.07 \\
\hline RUS & 1.00 & 0.97 & 0.97 & & & 0.75 & 0.89 & 0.13 & 0.01 \\
\hline SVK & 0.99 & 0.95 & & & & 0.51 & 0.67 & 0.16 & 0.11 \\
\hline SVN & 1.17 & 1.01 & 1.00 & 0.98 & & 0.65 & 0.70 & 0.06 & 0.06 \\
\hline SWE & 1.23 & 1.06 & 1.02 & 1.00 & & 0.75 & 0.77 & 0.02 & 0.06 \\
\hline TUR & 0.97 & 0.94 & & & & 0.65 & 0.86 & 0.21 & 0.04 \\
\hline TWN & 1.19 & 1.03 & 1.00 & 0.98 & & 0.67 & 0.73 & 0.06 & 0.07 \\
\hline USA & 1.32 & 1.15 & 1.09 & 1.06 & 1.03 & & 0.91 & & 0.02 \\
\hline
\end{tabular}




\section{Appendix}

\subsection{Multiple sectors}

Consider a two type/two sector version of the model. To incorporate a second sector, we follow convention by assuming a two-tier utility function in which the upper level is Cobb-Douglas and the lower level is CES. Specifically assume $U=Q_{1}^{\gamma_{1}} Q_{2}^{\gamma_{2}}$. Since the only variation across consumers within a country is income, we have:

$$
Q_{s}^{I}=\frac{\gamma_{s} \bar{m}^{I}}{P_{s}^{I}} \quad \text { where } P_{s}^{I}=\left[\sum_{v}\left(p_{v, s}^{I}\right)^{\frac{\rho_{s}}{\rho_{s}-1}}\right]^{\frac{\rho_{s}-1}{\rho_{s}}} \quad \& \quad s \in\{1,2\} .
$$

In this expanded model demand for variety $v$ in sector $s$ targeted to consumer $I$ is given by $p_{v, s}^{I}=\theta_{s}^{I} q_{v, s}^{\rho_{s}-1}$ with $\theta_{s}^{I}=\frac{\gamma_{s} \bar{m}^{I}}{\left(Q_{s}^{I}\right)^{\rho_{s}}}$. The equilibrium conditions for product design are a straightforward extension of (11):

$$
\beta \phi_{s}^{\rho_{s}}+(1-\beta) \phi_{s}=v
$$

$\bar{m}^{I}$ also has a familiar form:

$$
\bar{m}^{H}=\frac{\left(m^{H}-m^{L}\right)}{\sum_{s} \frac{\gamma_{s}}{\rho_{s}}\left(1-\phi_{s}^{\rho_{s}}\right)}, \quad \bar{m}^{L}=\frac{m^{L}}{\sum_{s} \frac{\gamma_{s}}{\rho_{s}}} .
$$

Let's confirm that expenditure shares vary with income. The menus are analogous to the single sector setting with the addition of a subscript $s$ to track sectors:

$$
T_{s}^{L}=\frac{\gamma_{s} \bar{m}^{L}}{n_{s} \rho_{s}} \quad T_{s}^{H}=\frac{\gamma_{s} \bar{m}^{H}\left(1-\phi_{s}^{\rho_{s}}\right)}{n_{s} \rho_{s}}+\frac{\gamma_{s} \bar{m}^{L}}{n_{s} \rho_{s}}
$$

Using these prices, along with (31) and recalling $\eta=\frac{m^{L}}{m^{H}}$, the expenditure shares for sector 1 are:

$$
s_{1}^{L}=\frac{n_{1} T_{1}^{L}}{m^{L}}=\frac{\gamma_{1} \rho_{2}}{\gamma_{2} \rho_{1}+\gamma_{1} \rho_{2}}, \quad s_{1}^{H}=(1-\eta) \frac{\gamma_{1} \rho_{2}\left(1-\phi_{1}^{\rho_{1}}\right)}{\gamma_{2} \rho_{1}\left(1-\phi_{2}^{\rho_{2}}\right)+\gamma_{1} \rho_{2}\left(1-\phi_{1}^{\rho_{1}}\right)}+\eta s_{1}^{L} .
$$

It follows immediately that $s_{1}^{L} \neq s_{1}^{H}$ provided $\rho_{1} \neq \rho_{2}$. So variation in rent extracting ability across sectors gives rise to variation in expenditures shares across income groups. Hence, the model predicts non-linear Engel curves.

This finding connects the analysis to the previous literature that attributes all of the variation in expenditure shares across income groups to preferences - specifically nonhomotheticities. In particular, this result suggests that at least part of the observed variation may be due to firm behavior rather than preferences. This distinction is important since variation driven by preferences is not necessarily associated with inefficiencies. However, to the extent that the variation is driven by firm behavior via SDPD, then the equilibrium will be inefficient. Moreover, the inefficiency in one sector tends to permeate the entire economy - even in a Cobb-Douglas model which usually isolates the outcomes in one sector from having an impact on another. This suggests novel welfare implications both within an economy, since the variation in expenditure shares are driven by distortions, and also due to increased international integration, since these distortions are based on the distribution of income (and integration alters the reference distribution from the national to the global distribution). 


\subsection{Proof of Proposition 3}

The central claim is that there exists a trade cost, $\bar{\tau}$, such that above this trade cost the gains from trade are equivalent to the standard model and below that level the gains are manifestly different. Begin by considering trade costs that are sufficiently high that markets are segmented. In order for the gains from trade to be the same as the standard model we require that relative product design is not altered by trade barriers. We know that each isolated market has a unique equilibrium with the relative design in each market given by $\phi_{i}$. If firms from $j$ ship to $i$ then the first order conditions under segmentation are:

$$
\begin{aligned}
\frac{\partial \pi_{j}}{\partial q_{i j}^{H}} & =\theta_{i}^{H}\left(q_{i j}^{H}\right)^{\rho-1}-\tau w_{j}=0 \\
\frac{\partial \pi_{j}}{\partial q_{i j}^{L}} & =\left(\theta_{i}^{L}-\beta_{i} \theta_{i}^{H}\right)\left(q_{i j}^{L}\right)^{\rho-1}-\beta^{L} \tau w_{j}=0
\end{aligned}
$$

However, it is immediately apparent that combining (33) and (34) reproduces the equilibrium conditions (11) and (14) which are solely a function of the distribution of income in country $i$ and $\rho$. Consequently, under segmentation firms from both locations offer the product line $\phi_{i}$ in country $i$.

To show the existence of $\bar{\tau}$, note that it's the location of the outside option which is relevant - is the next best option within a product line local or not? Under segmentation the next best option is always strictly the local option. To illustrate the existence of $\bar{\tau}$ consider a setting where $\phi_{f}>\phi_{h}$ (i.e. $\beta_{h}>\beta_{f}$ ) which implies that within a Foreign firm's product line the product designed for the low income consumer in $f$ is superior to the product designed for the low income consumer $h$. Since the information rents of the high income consumer are determined by the product offered to a low type, the relevant no arbitrage condition is:

$$
\left(\theta_{h}^{H}-\theta_{h}^{L}\right) \frac{\left(q_{h f}^{L}\right)^{\rho}}{\rho}>\left(\frac{\theta_{h}^{H}}{\tau^{\rho}}-\theta_{f}^{L}\right) \frac{\left(q_{f f}^{L}\right)^{\rho}}{\rho}
$$

This condition clearly holds for $\tau$ sufficiently high, so a segmentation equilibrium can be constructed based on trade costs. However, this arbitrage condition is violated if $\tau$ is sufficiently small. To see this assume that segmentation is viable under free trade $(\tau=1)$. From balanced trade it follows that wages will be equalized, generating a common cost structure across countries and delivering the same net income for the low income groups in both locations; $\bar{m}_{h}^{L}=\bar{m}_{f}^{L}=\rho L^{L}$. Recognizing that free trade also implies $q_{h f}^{L}=q_{h h}^{L}$ the no arbitrage constraint can be expressed as:

$$
\theta_{h}^{H} \frac{\left(q_{h h}^{H}\right)^{\rho}}{\rho}\left(\frac{q_{h h}^{L}}{q_{h h}^{H}}\right)^{\rho}-L^{L}>\theta_{h}^{H} \frac{\left(q_{h h}^{H}\right)^{\rho}}{\rho}\left(\frac{q_{f f}^{L}}{q_{h h}^{H}}\right)^{\rho}-L^{L} \Rightarrow q_{h h}^{L}=\frac{\bar{m}^{L}}{n p_{h}^{L}}>q_{f f}^{L}=\frac{\bar{m}^{L}}{n p_{f}^{L}}
$$

The marginal price for the low type in each location is given by $p_{i}^{L}=\frac{v_{i}}{\phi_{i}}=\frac{\bar{m}^{L} / \bar{m}_{i}^{H}}{\phi_{i}}$. Consequently, the no arbitrage condition requires:

$$
p_{h}^{L}<p_{f}^{L} \Rightarrow \frac{L^{L}}{L^{H}-L^{L}}\left(\frac{1-\phi_{h}^{\rho}}{\phi_{h}^{\rho}}\right)<\frac{L^{L}}{L^{H}-L^{L}}\left(\frac{1-\phi_{f}^{\rho}}{\phi_{f}^{\rho}}\right)
$$

Since this holds when $\phi_{h}>\phi_{f}$, we have a contradiction and the no arbitrage constraint is violated under the segmentation assumption. This confirms the existence of a $\bar{\tau}$ such that 
above this level markets are segmented and below this level markets begin to integration. When markets are partially integrated, the optimal design for low income groups are now linked for a Foreign firm as (35) binds for $\tau<\bar{\tau}$, resulting in $q_{h f}^{L \rho}=\left(\frac{\theta_{h}^{M} / \tau^{\rho}-\theta_{f}^{L}}{\theta_{h}^{M}-\theta_{h}^{L}}\right) q_{f f}^{L \rho}$.

Note that it is not necessarily the case that at $\bar{\tau}$ the low income markets are integrated within a Home firm's product line - it is possible that they are still segmented. This implies that product design below $\bar{\tau}$ will vary by income group, location and firm nationality - so the relative design in country $i$, by a firm in $j$ is $\phi_{i j}$.

The gains from trade for a member of a high income group are:

$$
\frac{U_{i \mathcal{T}}^{H}}{U_{i \mathcal{A}}^{H}}=\frac{\tilde{n}_{i}^{\frac{1}{\rho}} q_{i i}^{H}}{n_{i}^{\frac{1}{\rho}} q_{i \mathcal{A}}^{H}}=\frac{\tilde{n}_{i}^{\frac{1}{\rho}} \frac{\bar{m}_{i}^{H}}{n_{i}^{\frac{1}{\rho} w_{i}}}}{n_{i \mathcal{A}}^{\frac{1}{n_{i}}}}
$$

To complete the derivation requires the net income for a high type.

$$
\begin{gathered}
\rho T_{i i}^{H}=\left(1-\phi_{i i}^{M H \rho}\right) \frac{\bar{m}_{i}^{H}}{\tilde{n}_{i}}+\rho T_{i i}^{L} \quad \& \quad \rho T_{i j}^{H}=\left(1-\phi_{i j}^{M H \rho}\right) \frac{d_{i} \bar{m}_{i}^{H}}{\tilde{n}_{i}}+\rho T_{i j}^{L} \\
\rho\left(n_{i} T_{i i}^{H}+n_{j} T_{i j}^{H}\right)=\bar{m}_{i}^{H}\left(\frac{n_{i}}{\tilde{n}_{i}}+\frac{d_{i} n_{j}}{\tilde{n}_{i}}\right)-\bar{m}_{i}^{H}\left(\frac{n_{i}}{\tilde{n}_{i}} \phi_{i i}^{\rho}+\frac{d_{i} n_{j}}{\tilde{n}_{i}} \phi_{i j}^{\rho}\right)+\rho m_{i}^{L} \\
\Rightarrow \bar{m}_{i}^{H}=\frac{\rho\left(m_{i}^{H}-m_{i}^{L}\right)}{1-\bar{\phi}_{i \tau}^{\frac{1}{\rho}}}
\end{gathered}
$$

Hence

$$
\frac{U_{i \mathcal{T}}^{H}}{U_{i \mathcal{A}}^{H}}=\left(\frac{1-\phi_{i \mathcal{A}}^{\rho}}{1-\bar{\phi}_{i \tau}^{\frac{1}{\rho}}}\right)\left(\frac{\tilde{n}_{i}}{n_{i}}\right)^{\frac{1-\rho}{\rho}}
$$

While the gains for someone with low income are:

$$
\begin{aligned}
\frac{U_{i \mathcal{T}}^{L}}{U_{i \mathcal{A}}^{L}} & =\frac{\left(n_{i}\left(q_{i i}^{L}\right) \rho+n_{j}\left(q_{i j}^{L}\right) \rho\right)^{\frac{1}{\rho}}}{n_{i}^{\frac{1}{\rho}} q_{i \mathcal{A}}^{L}}=\frac{\left(n_{i} \phi_{i i}^{\rho}\left(q_{i i}^{H}\right)^{\rho}+n_{j} \phi_{i j}^{\rho}\left(q_{i j}^{H}\right)^{\rho}\right)^{\frac{1}{\rho}}}{n_{i}^{\frac{1}{\rho}} \phi_{i \mathcal{A}} q_{i \mathcal{A}}^{H}} \\
& =\frac{\bar{\phi}_{i \tau} \tilde{n}_{i}^{\frac{1}{\rho}} q_{i i}^{H}}{\phi_{i \mathcal{A}} n_{i}^{\frac{1}{\rho}} q_{i \mathcal{A}}^{H}}
\end{aligned}
$$

\subsection{Proof of Lemma 1}

Consider a setting where $\beta_{f}=0, \beta_{h}=1$, there are $N$ countries of each type and $1<\tau<\bar{\tau}$. In this case the high and low income types are located in different countries and the residual demand curves can be identified exclusively by income superscripts. Assume that trade costs are sufficiently small that no markets are segmented within a firm's product line international arbitrage constraints bind. This implies that firms in $f$ are constrained to offer the same low end product, $q_{f f}^{L}$, to its domestic low income consumers and the low income consumers in the other countries with $\beta_{f}$. That is, despite $\tau>1$, both $\beta_{f}$ countries are offered the same product by both local and foreign $f$ firms. 
Since markets are partially integrated, it follows that the incentive constraint for a high type binds with respect to the product designed for the low income type in $f$. For a firm located in $f$, the incentive constraint implies the following price: $T_{h f}^{H}=\theta^{H} \frac{\left(q_{h f}^{H}\right)^{\rho}}{\rho}-$ $\left(\frac{\theta^{H}}{\tau^{\rho}}-\theta^{L}\right) \frac{\left(q_{f f}^{L}\right)^{\rho}}{\rho}$. The objective function for a firm in $f$ is then:

$\pi_{f}=N\left(\theta^{H} \frac{\left(q_{h f}^{H}\right)^{\rho}}{\rho}-\tau w_{f} q_{h f}^{H}\right)+N\left(2 \theta^{L}-\frac{\theta^{H}}{\tau^{\rho}}\right) \frac{\left(q_{f f}^{L}\right)^{\rho}}{\rho}-(1+(N-1) \tau) w_{f} q_{f f}^{L}-w_{f} F$.

Combining the first order conditions for $q_{h f}^{H}$ and $q_{f f}^{L}$ and defining $\phi_{h f}=q_{f f}^{L} / q_{h f}^{H}$ gives:

$$
\left(\frac{2 \theta^{L}}{\theta^{H}}-\frac{1}{\tau^{\rho}}\right) \phi_{h f}^{\rho-1}=\frac{1+(N-1) \tau}{N \tau}
$$

For $h$ firms, the domestic market is high income, along with $N-1$ of its export markets and the other $N$ export markets are low income. One again international arbitrage constraints are assumed to bind. To distinguish domestic high income product, $q_{h h}^{H}$, from the high income export market we will use a subscript $x, q_{x h}^{H}$. A firm in $h$ has the following objective function:

$$
\begin{aligned}
\pi_{h}=\theta^{H} \frac{\left(q_{h h}^{H}\right)^{\rho}}{\rho}-w_{h} q_{h h}^{H}+(N-1) & \left(\theta^{H} \frac{\left(q_{x h}^{H}\right)^{\rho}}{\rho}-w_{h} \tau q_{x h}^{H}\right) \\
& +N\left(\left(2 \theta^{L}-\frac{\theta^{H}}{\tau^{\rho}}\right) \frac{\left(q_{f h}^{L}\right)^{\rho}}{\rho}-\tau w_{h} q_{f h}^{L}\right)-w_{h} F
\end{aligned}
$$

Combining the first order conditions for $q_{x h}^{H}$ and $q_{f h}^{L}$ and defining $\phi_{x h}=q_{f h}^{L} / q_{x h}^{H}$ gives:

$$
\left(\frac{2 \theta^{L}}{\theta^{H}}-\frac{1}{\tau^{\rho}}\right) \phi_{x h}^{\rho-1}=1
$$

Using these conditions we have $\phi_{h f}>\bar{\phi}_{f}>\bar{\phi}_{h}>\phi_{x h}$ when markets are partially integrated.

\subsection{Many income groups}

Assume that there are $\bar{I}$ income groups, $I \in[1, \ldots ., \bar{I}]$, with the groups ordered $m^{I}<m^{I+1}$. In addition define $J \equiv \min \{I+1, \bar{I}\}$ - the income group immediately above group $I$ (with the appropriate adjustment when $I=\bar{I}$ ). The $\bar{I}$ type case generates the following objective function for a typical firm:

$$
\pi=\sum_{I} \beta^{I}\left(T^{I}-w q^{I}\right)-w F
$$

subject to

$$
\begin{aligned}
& \theta^{I} \frac{\left(q^{I}\right)^{\rho}}{\rho}-T^{I} \geq \theta^{I} \frac{\left(q^{K}\right)^{\rho}}{\rho}-T^{K}, \forall I \neq K \\
& \theta^{I} \frac{\left(q^{I}\right)^{\rho}}{\rho}-T^{I} \geq 0, \forall I
\end{aligned}
$$


where (38) are the incentive compatibility constraints while (39) are the participation constraints. Recognizing that the participation constraint binds for the lowest type and the incentive constraints bind for the other types, we have:

$$
\max _{\left\{q^{I}\right\}} \pi=\sum_{I=1}^{\bar{I}} \beta^{I}\left(\theta^{I} \frac{\left(q^{I}\right)^{\rho}}{\rho}-w q^{I}-\left(\theta^{J}-\theta^{I}\right) \frac{\left(q^{I}\right)^{\rho}}{\rho} \frac{P\left[m>m^{I}\right]}{\beta^{I}}\right)-w F
$$

where $P\left[m>m^{I}\right]=\sum_{I+1}^{\bar{I}} \beta^{I}$.

Taking first order conditions gives:

$$
\frac{\partial \pi}{\partial q^{I}}=\beta^{I} \theta^{I}\left(q^{I}\right)^{\rho-1}-\left(\theta^{I}-\theta^{I}\right)\left(q^{I}\right)^{\rho-1} P\left[m>m^{I}\right]=\beta^{I} w
$$

Note in particular for the highest income group, $\bar{I}$, product design satisfies: $\theta^{\bar{I}}\left(q^{\bar{I}}\right)^{\rho-1}=w$. This allows (40) to be written as:

$$
\begin{gathered}
\beta^{I} \frac{\theta^{I}}{\theta^{\bar{I}}}\left(\frac{q^{I}}{q^{\bar{I}}}\right)^{\rho-1}-\frac{\left(\theta^{J}-\theta^{I}\right)}{\theta^{\bar{I}}}\left(\frac{q^{I}}{q^{\bar{I}}}\right)^{\rho-1} P\left[m>m^{I}\right]=\beta^{I} \\
P\left[m \geq m^{I}\right] \frac{\theta^{I}}{\theta^{\bar{I}}}\left(\frac{q^{I}}{q^{\bar{I}}}\right)^{\rho-1}-\frac{\theta^{J}}{\theta^{\bar{I}}}\left(\frac{q^{I}}{q^{\bar{I}}}\right)^{\rho-1} P\left[m>m^{I}\right]=\beta^{I}
\end{gathered}
$$

To account for the variation across the $\bar{I}$ types we introduce the following notation conventions: $\phi^{I}=\frac{q^{I}}{q^{I}}$ and $v^{I}=\frac{\bar{m}^{I}}{\bar{m}^{\bar{l}}}$. Using (41) and symmetry (i.e. $\left.\theta^{I} / \theta^{\bar{I}}=v^{I} /\left(\phi^{I}\right)^{\rho}\right)$ the equilibrium product design for the $\bar{I}-1$ income groups solves:

$$
\frac{P\left[m>m^{I}\right]}{P\left[m \geq m^{I}\right]} \frac{v^{J}}{\left(\phi^{J}\right)^{\rho}}\left(\phi^{I}\right)^{\rho}+\frac{\beta^{I}}{P\left[m \geq m^{I}\right]} \phi^{I}=v^{I}
$$

where $\bar{m}^{I}=\frac{\rho\left(m^{I}-m^{\ell}\right)}{1-\left(\phi^{\ell} / \phi^{I}\right)^{\rho}}, \ell=(I-1), m^{0}=0, \phi^{0}=0$.

\subsection{Derivation of equation (28)}

The utility derived by a high income type in country $i$ trading with $j$ partners is given by:

$$
U_{i}^{\bar{I}}=\left(\sum n_{j}\left(q_{i j}^{\bar{I}}\right)^{\rho}\right)^{\frac{1}{\rho}}
$$

To make progess consider the first order condition of a firm in $j$ serving high types in $i$ :

$$
\frac{\partial \pi_{j}}{\partial q_{i j}^{\bar{I}}}=\theta_{j}^{\bar{I}}\left(q_{i j}^{\bar{I}}\right)^{\rho-1}=\tau_{i j} w_{j}
$$

Taking the ratio of these conditions across firms in $i$ and $j$ implies $\left(q_{i j}^{\bar{I}}\right)^{\rho}=d_{i j}\left(q_{i i}^{\bar{I}}\right)^{\rho}$, where $d_{i j}=\left(\frac{\tau_{i j} w_{j}}{w_{i}}\right)^{1-\sigma}$. Furthermore, these first order conditions must hold in equilibrium. So the location of the residual demand function is given by $\theta_{i}^{\bar{I}}=\frac{\bar{m}_{i}^{\bar{I}}}{\left(Q_{i}^{\bar{I}}\right)^{\rho}}=\frac{\bar{m}_{i}^{\bar{I}}}{\sum n_{j}\left(q_{i j}^{\bar{I}}\right)^{\rho}}=\frac{\bar{m}_{i}^{\bar{I}}}{\sum n_{j} d_{i j}\left(q_{i i}^{\bar{I}}\right)^{\rho}}=$ $\frac{\bar{m}_{i}^{\bar{I}}}{\tilde{n}_{i}\left(q_{i i}^{I}\right)^{\rho}}$. Combining this with the first order condition for a firm in $i$ gives $q_{i i}^{\bar{I}}=\frac{\bar{m}_{i}^{\bar{I}}}{\tilde{n}_{i} w_{i}}$. 
Using the equilibrium relationship between $q_{i j}^{\bar{I}}$ and $q_{i i}^{\bar{I}}$, along with the equilibrium value of $q_{i i}^{\bar{I}}$ allows (43) to be written as:

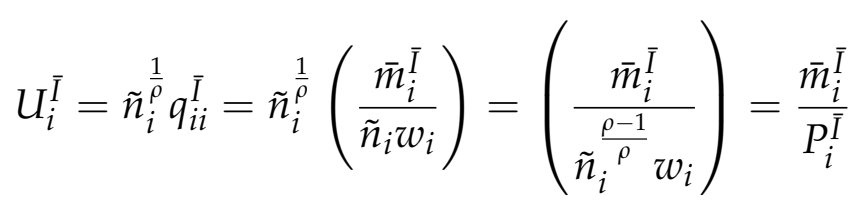

where $P_{i}^{\bar{I}}$ is the ideal price index for the high income group in $i$.

The welfare measure for group $I$ in country $i$ follows from:

$$
\begin{aligned}
U_{i}^{I} & =\left(\sum n_{j}\left(q_{i j}^{I}\right)^{\rho}\right)^{\frac{1}{\rho}}=\left(\sum n_{j}\left(\frac{q_{i j}^{I}}{q_{i j}^{\bar{I}}}\right)^{\rho}\left(q_{i j}^{\bar{I}}\right)^{\rho}\right)^{\frac{1}{\rho}}=\left(\sum d_{i j} n_{j}\left(\phi_{i j}^{I}\right)^{\rho}\left(q_{i i}^{\bar{I}}\right)^{\rho}\right)^{\frac{1}{\rho}} \\
& =\bar{\phi}_{i}^{I} U_{i}^{\bar{I}}
\end{aligned}
$$




\section{References}

Antràs, Pol, and R. W. Staiger (2012) 'Trade agreements and the nature of price determination.' The American Economic Review pp. 470-476

Arkolakis, Costas, Arnaud Costinot, and Andres Rodriguez-Clare (2012) 'New Trade Models, Same Old Gains?' The American Economic Review 102(1), 94-130

Busse, Meghan, Marc Rysman et al. (2005) 'Competition and price discrimination in yellow pages advertising.' RAND Journal of Economics 36(2), 378-390

Choi, Y.C., D. Hummels, and C. Xiang (2009) 'Explaining Import Quality: The Role of the Income Distribution.' Journal of International Economics 78(2), 293-303

Clerides, Sofronis K (2002) 'Book value: intertemporal pricing and quality discrimination in the us market for books.' International Journal of Industrial Organization 20(10), 1385-1408

Cohen, Andrew (2011) 'Identifying price discrimination when product menus are endogenous.' Southern Economic Journal 77(3), 674-691

Costinot, Arnaud, and Andres Rodriguez-Clare (2014) 'Trade theory with numbers: Quantifying the consequences of globalization.' Handbook of International Economics 4, 197

Crawford, Gregory S, and Matthew Shum (2007) 'Monopoly quality degradation and regulation in cable television.' Journal of Law and Economics 50(1), 181-219

Eizenberg, Alon (2014) 'Upstream innovation and product variety in the us home pc market.' The Review of Economic Studies 81(3), 1003-1045

Fajgelbaum, P., G.M. Grossman, and E. Helpman (2011) ‘Income Distribution, Product Quality, and International Trade.' Journal of Political Economy 119(4), 721-765

Fajgelbaum, Pablo D, and Amit K Khandelwal (2015) 'Measuring the unequal gains from trade.' Quarterly Journal of Economics

Fieler, A.C. (2011) 'Nonhomotheticity and bilateral trade: evidence and a quantitative explanation.' Econometrica 79(4), 1069-1101

Hendel, Igal, and Aviv Nevo (2013) 'Intertemporal price discrimination in storable goods markets.' American Economic Review 103(7), 2722-51

Krugman, Paul (1980) 'Scale economies, product differentiation, and the pattern of trade.' The American Economic Review pp. 950-959

Lakner, Christoph, and Branko Milanovic (2015) 'Global income distribution: From the fall of the berlin wall to the great recession.' The World Bank Economic Review

Markusen, James R (2013) 'Putting per-capita income back into trade theory.' Journal of International Economics 90(2), 255-265

Marshall, Guillermo (2015) 'Hassle Costs and Price Discrimination: An Empirical Welfare Analysis.' American Economic Journal: Applied Economics 7(3), 123-146

Maskin, E., and J. Riley (1984) 'Monopoly with incomplete information.' The RAND Journal of Economics 15(2), 171-196 
McCalman, Phillip (2010) 'Trade policy in a "Super Size Me" World.' Journal of International Economics 81(2), 206-218

_ (2016a) 'Market size, international trade and product lines'

_ (2016b) 'Supersizing international trade'

- (2017) 'International trade, product lines and welfare: The roles of firm and consumer heterogeneity'

McCalman, Phillip, and Alan Spearot (2013) 'Why trucks jump: Offshoring and product characteristics.' Journal of International Economics 91(1), 82-95

McManus, Brian (2007) 'Nonlinear pricing in an oligopoly market: The case of specialty coffee.' The RAND Journal of Economics 38(2), 512-532

Melitz, Marc J, and Gianmarco IP Ottaviano (2008) 'Market size, trade, and productivity.' The review of economic studies 75(1), 295-316

Miravete, Eugenio J, and Lars-Hendrik Röller (2003) 'Competitive non-linear pricing in duopoly equilibrium: the early us cellular telephone industry'

Nosko, Chris (2010) 'Competition and quality choice in the cpu market.' Manuscript, Harvard University

Palazzolo, Mike, and A Yesim Orhun (2016) 'Frugality is hard to afford'

Phillips, Robert Lewis (2005) Pricing and revenue optimization (Stanford University Press)

Shapiro, Carl, and Hal R Varian (1998) 'Versioning: the smart way to.' Harvard Business Review 107(6), 107

Shepard, Andrea (1991) 'Price discrimination and retail configuration.' Journal of Political Economy pp. 30-53

Simonovska, Ina (2015) 'Income differences and prices of tradables: Insights from an online retailer.' The Review of Economic Studies 82(4), 1612-1656

Tarasov, Alexander (2012) 'Trade liberalization and welfare inequality: A demand-based approach.' The Scandinavian Journal of Economics 114(4), 1296-1317

Thomas, Catherine (2011) 'Too many products: Decentralized decision making in multinational firms.' American Economic Journal: Microeconomics 3(1), 280-306

Verboven, Frank (2002) 'Quality-based price discrimination and tax incidence: evidence from gasoline and diesel cars.' RAND Journal of Economics pp. 275-297 